\title{
Fuerzas motrices y perspectivas de la revolución rusa Karl Kautsky, 1906
}

\section{Driving forces and prospects of the Russian revolution Karl Kautsky, 1906}

\author{
Daniel Gaido* \\ Paula Ávila** \\ Editores.** $^{* * *}$
}

\begin{abstract}
Resumen
En octubre de 1906 G. V. Plejánov envió un cuestionario a líderes de la socialdemocracia internacional, solicitándoles formalmente su opinión sobre el carácter de clase de la revolución rusa y las tácticas que de dicho análisis de desprendían para el Partido Obrero Socialdemócrata de Rusia. Recibió doce respuestas, que en su gran mayoría apoyaban la postura menchevique: la revolución rusa no es socialista, a lo sumo es burguesa con elementos socialistas, el boicot a la Duma es considerado un error y la cooperación con los partidos de la oposición burguesa, esencial. La excepción a dicha regla fue la respuesta de Karl Kautsky, que tradujimos y editamos por primera vez en castellano para el presente artículo. Si bien la respuesta es cautelosa y lo suficientemente ambigua para que tanto Lenin como Trotsky la consideren como una ratificación de sus teorías, es categórica en rechazar la posibilidad de una coalición con la burguesía, la postura que Plejánov avalaba, y por ende constituye una clara refutación de las perspectivas mencheviques de la revolución rusa. Más aún, Trotsky, en el prefacio a la antología En defensa del partido, fechado 1 de enero de 1907, que incluimos en el presente artículo, se refirió al trabajo de Kautsky como una
\end{abstract}

\footnotetext{
* Argentino, Ph.D. (2000), Universidad de Haifa (Israel), es investigador adjunto del Consejo Nacional de Investigaciones Científicas y Técnicas (CONICET). Es autor de The Formative Period of American Capitalism (London: Routledge, 2006) y co-editor, junto con Richard B. Day, de Witnesses to Permanent Revolution: The Documentary Record (Brill, 2009, Haymarket, 2011) y Discovering Imperialism: Social Democracy to World War I (Brill, 2011, Haymarket, 2012). danielgaid@gmail.com

Argentina, Licenciada en historia, investigadora independiente, docente auxiliar de Historia Contemporánea Universidad Nacional de Córdoba, Escuela de Historia, paula.a.avila@gmail.com

Fuente: Karl Kautsky, 'Triebkräfte und Aussichten der russischen Revolution', Die neue Zeit, 25. 1906-1907, 1. Bd., H. 9-10, S. 284-290, 324-333.
} 
reivindicación de sus ideas sobre la revolución permanente, tal como la expuso en su famoso libro Resultados y Perspectivas, originalmente publicado en 1906.

Palabras clave: revolución rusa - Karl Kautsky - Lenin - Trotsky - revolución permanente

\begin{abstract}
In October 1906 GV Plekhanov sent a questionnaire to the leaders of international Social Democracy, formally requesting their opinion about the class character of the Russian revolution and the tactics which followed from this analysis for the Russian Social Democratic Labour Party. He received twelve responses, which overwhelmingly supported the Menshevik position: the Russian revolution is not socialist, at most it is bourgeois revolution with socialist elements; the boycott of the Duma is considered an error and cooperation with the parties of the bourgeois opposition, essential. The exception to this rule was the response of Karl Kautsky, which we have translated and edited for the first time in Spanish for this article. While Kautsky's answer is cautious and ambiguous enough so that both Lenin and Trotsky considered it as a confirmation of their theories, it categorically rejected the possibility of a coalition with the bourgeoisie, the posture favoured by Plekhanov, and therefore constitutes a clear refutation of the Menshevik prospects on the Russian revolution. Moreover, Trotsky, in the preface to the anthology In Defense of the Party, dated January 1, 1907, which we have also included in this article, referred to Kautsky's work as a vindication of his ideas on permanent revolution, as presented in his famous book Results and Prospects, originally published in 1906.
\end{abstract}

Keywords: Russian Revolution - Karl Kautsky - Lenin - Trotsky - permanent revolution

\title{
Introducción
}

“Fuerzas motrices y perspectivas de la revolución rusa” es el título del artículo de Karl Kautsky que surge como respuesta al cuestionario que G. V. Plejánov envió en octubre de 1906 a líderes de la socialdemocracia internacional, solicitándoles formalmente su opinión sobre la situación rusa:

"La importancia creciente para el movimiento obrero mundial de la opinión del socialismo internacional me incita a recurrir a usted ... para conocer sus puntos de vista sobre la situación extraordinariamente seria en la que se encuentra actualmente Rusia. [...]

1) ¿Cuál es el carácter general de la Revolución rusa? ¿Estamos frente a una revolución burguesa o socialista? 
2) En vista de los desesperados esfuerzos realizados por el gobierno ruso para aislar el movimiento revolucionario, ¿cuál debería ser la posición del partido Social-Demócrata ruso respecto a la burguesía democrática, la cual, a su manera, también pelea por la libertad política?

3) ¿Cómo pueden las tácticas del partido de la Social Democracia, respecto a las elecciones a la Duma, utilizar las fuerzas de los partidos de la oposición burguesa en la lucha contra el antiguo régimen, y al mismo tiempo permanecer fiel al punto de vista de la resolución de Amsterdam?” (Baron 1995, pp. $117-18$ y 120). ${ }^{1}$

Recibe doce respuestas de figuras británicas (Harry Quelch y Fedor Rotshtein), belgas (Camille Huysmans, Emile Vandervelde, y Edouard Anseele), francesas (Jules Guesde, Paul Lafargue, Edouard Vaillant, y Edgar Milhaud), italianas (Enrico Ferri y Filippo Turati), y una alemana (Karl Kautsky), de las cuales once son publicadas en Sovremennaia zhizn' (Vida Moderna) (Baron 1995, p. 118). En parte debido a la forma en que son redactadas las preguntas (forma que Lenin abiertamente califica de subterfugio y Trotsky sutilmente ironiza respecto de su carácter “ideológicamente imparcial”), las respuestas en su conjunto, apoyan la postura Menchevique: la revolución rusa no es socialista, a lo sumo es burguesa con elementos socialistas, el boicot a la Duma es considerado un error y la cooperación con los partidos de la oposición burguesa, esencial.

La respuesta de Kautsky fue la única que no fue publicada por Plejánov, aunque sí por el mismo Kautsky en Die neue Zeit como un artículo en dos entregas, y también en cuatro ediciones rusas, una con un prefacio de Trotsky (Trotsky 1907, pp. 122-48) y otra con uno de Lenin (Kautsky 1906, pp. 1-7; Lenin 1906a, pp. 408-13), ambos incluidos en esta traducción.

Podemos imaginarnos las razones de la no publicación de la respuesta de Kautsky por Plejánov. Si bien la respuesta es cautelosa y lo suficientemente ambigua para que tanto Lenin como Trotsky la consideren como una ratificación de sus teorías, es categórica en rechazar la posibilidad de una coalición con la burguesía, la postura que Plejánov avalaba. Trotsky expone claramente esta táctica de Plejánov en su artículo Tres concepciones de la Revolución Rusa de 1939, al mencionar que éste separaba la revolución burguesa de la revolución socialista, estableciendo para cada una de ellas combinaciones de fuerzas diferentes y momentos distintos. La conquista de la libertad política era una tarea de la revolución burguesa, la cual sólo podía ser lograda por la burguesía liberal en alianza con el proletariado. La revolución socialista, llevada a cabo por el proletariado directamente

\footnotetext{
${ }^{1}$ El cuestionario fue publicado en Sovremennaia zhizn' (Vida Moderna) nro. 11 (1906) p. 206. Si bien Plejánov permanecía en Ginebra, era editor de este periódico moscovita y como tal publicó el cuestionario y posteriormente las respuestas al mismo que seleccionó (Baron 1995).
} 
enfrentado con la burguesía, era pospuesta para un futuro indefinido cuando el desarrollo capitalista de las fuerzas productivas alcanzase un nivel superior (Trotsky 1939, p.56).

Más allá de la fallida intención de Plejánov de pretender apoyar su punto de vista en la opinión de uno de los grandes teóricos que produjo el marxismo, la respuesta que el cuestionario motiva de Kautsky muestra la dirección general del debate ideológico que tenía lugar en Rusia como consecuencia de los eventos de la Revolución de 1905. Dicho debate giraba, en el seno de la Socialdemocracia, en torno al carácter general de la Revolución Rusa y su dinámica interna de clase, planteando así concretamente la cuestión del poder revolucionario (Trotsky 2006, p. 13).

Las implicancias de este debate también son puestas de manifiesto por Trotsky:

El carácter de la revolución rusa era la cuestión principal alrededor de la cual se agrupaban, según la respuesta que daban, las diversas corrientes de ideas y organizaciones políticas en el movimiento revolucionario ruso. En la propia Socialdemocracia esta cuestión provocó, desde que comenzó a plantearse de forma concreta debido al curso de los acontecimientos, las divergencias de opiniones más grandes. Desde 1904, estas divergencias de opiniones se han expresado en dos corrientes básicas: el menchevismo y el bolchevismo (Trotsky 1906, p. 29).

Es importante recordar, ante estas divergencias en el seno de la Socialdemocracia rusa, que Kautsky, al no estar familiarizado con el idioma ruso y no poder leer los documentos rusos de manera directa, sin intermediarios, fue deliberadamente cuidadoso y ambiguo en su contestación, ya que no deseaba exacerbar las diferencias entre los socialdemócratas rusos, en particular sobre el rol del campesinado. Decimos que esta era una actitud deliberada, ya que, según Steenson, Kautsky estaba al tanto de las divisiones internas en el movimiento ruso, aunque no demasiado familiarizado con las diferencias tácticas, como él mismo lo afirma en el artículo (Steenson 1991, pp. 136-7). Tanto Lenin como Trotsky invocaron su autoridad para respaldar sus posturas, lo cual muestra el gran respeto que todos los círculos de la Social Democracia rusa sentían hacia Kautsky y la contundencia de su respuesta, que implicaba una refutación del menchevismo.

En concreto, Lenin afirmó en el prefacio a la traducción rusa del artículo de Kautsky que sus proposiciones eran una brillante confirmación de la táctica de los bolcheviques. También se manifestará en igual sentido en una crítica publicada en el periódico Proletarii, en esta ocasión invocando a Kautsky para apoyar su defensa de la posición de la Social Democracia revolucionaria contra el oportunismo (Lenin, 1906b, pp. 372-3).

Trotsky, por su parte, en el prefacio que incluimos a continuación, se refirió al trabajo de Kautsky como una reivindicación de sus ideas sobre la revolución permanente, tal como la expuso en Resultados y Perspectivas, encontrando entre ambos un desarrollo casi idéntico, circunstancia que encuentra de lo más gratificante. 
Esto no es algo aislado, por el contrario, Trotsky apeló en reiteradas oportunidades a la autoridad de Kautsky, tanto en la obra mencionada como así también en su libro 1905. Tampoco es casual, ya que Kautsky fue el primer marxista de Europa Occidental en emplear la teoría de la revolución permanente en conexión con los eventos del Imperio Ruso. Ayudó a iniciar el debate respecto a la revolución permanente en su artículo "Los eslavos y la revolución”, publicado en Iskra el 10 de marzo de 1902. En 1903 redactó la introducción a una edición polaca del Manifiesto Comunista, en la cual encontramos una referencia explícita a la "Circular del Comité Central de la Liga Comunista" de marzo de 1850 así como una mención a "una revolución burguesa que, al hacerse permanente, crece más allá de sus propios límites y se desarrolla como una revolución proletaria” (Kautsky 1904b). Luego del estallido de la revolución de 1905, Kautsky también empleó repetidamente la expresión “revolución permanente” en una serie de artículos publicados en julio en Die neue Zeit (Kautsky, 1905), bajo el título "Las consecuencias de la victoria japonesa y la Social Democracia.” En diciembre de 1905 Kautsky publicó el artículo "Vieja y Nueva Revolución”, donde declaraba que la Revolución Rusa "promete inaugurar [...] una era de revoluciones europeas que culminará con la dictadura del proletariado, preparando el camino para el establecimiento de una sociedad socialista” (1905b, pp. 35). Al mes siguiente, reimprimió la sección de su libro sobre la revolución francesa que describía la política de los sans-culottes en 1793-4 como una de estrategia de revolución permanente, en un folleto publicado en conmemoración del primer aniversario del “Domingo Sangriento” (Kautsky, “Die Sansculotten der französischen Revolution” originalmente publicado como Kaustky 1889b - en Kautsky 1906a, pp. 11-12). La serie de estas publicaciones donde se hacen referencias expresas a la teoría de la revolución permanente se completa con el artículo incluido en esta traducción.

Esto ayudará, esperamos, a superar la visión anacrónica del Kautsky anterior a 1910 como un apóstol del quietismo y como un reformista oculto tras una fraseología revolucionaria, un anacronismo que ya fue objeto de crítica por su principal biógrafo, Marek Waldenberg. En su libro, que lamentablemente no fue traducido al español, considera que no es correcto juzgar toda la obra de Kautsky en función de sus ideas posteriores al estallido de la guerra. Esta postura es propia de aquellos que, como Karl Korsch, ven su pensamiento como un todo que evolucionó desde un cripto-revisionismo a un revisionismo abierto (Waldenberg, 1980, p. 898.). En el obituario que Trotsky escribe con motivo del deceso de Kautsky en 1938 podemos ver con toda claridad, que ésta no era la postura de Lenin y Trotsky antes de la Primera Guerra Mundial. ${ }^{2}$

\footnotetext{
2 "Los intentos de la presente historiografía del Comintern para presentar las cosas como si Lenin, casi en su juventud, hubiera visto en Kautsky un oportunista y le hubiera declarado la guerra, son radicalmente falsos. Casi hasta la [Primera] Guerra Mundial, Lenin consideraba a Kautsky como el genuino continuador de la causa de Marx y Engels”. (Trotsky 1938, p. 98).
} 
Finalmente, creemos que es importante destacar dos ideas rectoras que pueden ayudar a una mejor comprensión del artículo de Kautsky:

- Primero, Kautsky advierte a sus lectores que la Revolución de 1905 los estaba enfrentando a situaciones completamente nuevas y a problemas para los que ningún modelo anterior era adecuado. "La historia no se repite": las analogías entre la revolución rusa y la gran revolución francesa no convertían a la primera en una simple repetición de la segunda (Trotsky 1906, p. 52) y mucho menos proporcionaban soluciones a los problemas acuciantes de la sociedad rusa. Como gran teórico del marxismo que era, Kautsky comprendía acabadamente que éste es un método de análisis de las relaciones sociales y como tal, existen riesgos en pretender convertir un comentario histórico relativo del marxismo en un teorema secular. ${ }^{3}$

- Segundo, Kautsky sostiene que la era de las revoluciones burguesas ha terminado en Europa. Con esto quiere decir que la burguesía ya no es una fuerza motriz de la revolución: es ahora el tiempo del proletariado, como clase independiente y con objetivos revolucionarios también independientes. Partir de esta noción hace absolutamente irrelevante el planteo de una posible coalición con la burguesía liberal. Esto es aplicable asimismo a Rusia, a pesar de su atraso secular: un país cuya superficie representaba la sexta parte de la superficie del planeta (5.400.000 kilómetros cuadrados de tierra en Europa y 17.500.000 en Asia), contaba en 1905 con una población de 150 millones de personas, de las cuales 1.430 .000 vivían en San Petersburgo y 1.100.000 en Moscú, y poseía la industria más concentrada de Europa combinada con la agricultura más atrasada. El estado de la autocracia zarista, a medio camino entre el absolutismo europeo y el despotismo asiático, era completamente parasitario y consumía una enorme proporción de la riqueza social en gastos militares y suntuarios. La inmensa mayoría de la población, dispersa en aldeas campesinas, contrastaba con los habitantes de las ciudades, que pasaron de ser centros administrativos a ser centros industriales, sin transitar el camino del artesanado y de los gremios. El proletariado, por ende, no tenía raíces artesanales sino que provenía directamente del campesinado y poseía una importancia económica extremadamente significativa a pesar de su debilidad numérica. Frente a él, se alzaba la burguesía compradora, en gran parte directamente extranjera o bien ligada a los subsidios del estado absolutista, y por ende políticamente cobarde. Esta clase social, que debería haber liderado la revolución democrática, tenía vínculos estrechos con la gran propiedad terrateniente, y aunque odiaba la autocracia, más aún temía al proletariado. La pequeña burguesía urbana era casi inexistente e incapaz de asumir las tareas de la revolución junto a la intelectualidad desclasada y radicalizada.

\footnotetext{
3 “La definición sociológica general de lo que es una revolución burguesa no determina en absoluto las tareas político tácticas, las contradicciones y los problemas que se presentan en el caso de una revolución burguesa concreta" (Trotsky 1906, p. 67).
} 
Las descripciones de la época abundan en detallar situaciones de una enorme miseria, descontento campesino y una opresión feroz de las minorías nacionales, que comprendían más de la mitad de la población del imperio ruso (aproximadamente el $55 \%) .{ }^{4}$

En este marco, la cuestión agraria surgía como ineludible. Como menciona Trotsky, la burguesía había cedido su carácter revolucionario al proletariado y también le cedería el liderazgo revolucionario del campesinado. La revolución podía ser burguesa por sus objetivos y resultados, pero nunca debía perderse de vista que el agente principal de la revolución era el proletariado, que sería empujado hacia el poder por el curso revolucionario y excedería los límites de las tareas democrático-burguesas y nacionales (Trotsky, 1939, p. 70).

\section{Introducción a la antología En defensa del partido \\ León Trotsky \\ (1 Enero 1907) ${ }^{5}$}

El último punto [...] es la traducción de un artículo de Kautsky: “Fuerzas Motrices y perspectivas de la Revolución Rusa”. Este artículo demostró ser un golpe inesperado para algunos camaradas que se conforman con concepciones comunes y utópicas sobre el curso de la Revolución rusa, concepciones que estaban muy lejos de cualquier análisis serio, cualquiera sea su contenido real. Ellos soñaron con una dictadura democrático-burguesa (Jacobina) cuyos toques finales serían dados aquí por la "unión de uniones”, es decir, por los Cadetes. ¡Pobre “unión de uniones”! ¡Pobres Cadetes!

Algunos amigos me dijeron, en broma por supuesto, que una leyenda muy poética fue inventada para debilitar el efecto que el artículo de Kautsky podría tener. Parvus, después de huir del distrito de Turujansk [Siberia] y en camino a la campaña electoral en el Rin [se dice que ha comenzado] su actividad en Friedland, Berlín, confundiendo el claro

\footnotetext{
${ }^{4}$ En 1897 menos del 13\% de la población de la Rusia europea vivía en ciudades, frente a un 41\% en Francia, $54 \%$ en Alemania y el 77\% en Gran Bretaña. Los campesinos seguían siendo aproximadamente las cuatro quintas partes de la población total. Según el censo de 1897 sólo el $25 \%$ de los hombres y el $10 \%$ de las mujeres fuera de las ciudades estaban alfabetizados. Según las estadísticas oficiales, un total de 2,2 millones de trabajadores estaban empleados en las industrias de minería y manufactura en 1900. Si se incluyen los que no estaban sujetos a la inspección de fábricas, se obtiene una cifra de aproximadamente dos millones y medio. A esto se puede añadir otro medio millón de empleados en el transporte y aproximadamente 300.000 obreros de la construcción en zonas urbanas, lo que arroja una cifra total de 3,3 millones de trabajadores. Esto representaba aproximadamente el 2,5\% de la población total de 129 millones en 1897. Antes de 1906 cualquier organización sindical independiente estaba expresamente prohibida por la ley. Hasta 1905 una huelga, aun cuando no estuviera organizada, era también un delito penal, por el que los responsables podían ser detenidos por un período de ocho meses (datos tomados de Keep 1963, pp. 1-10).

${ }^{5}$ Trotsky 1907, pp. 142-3.
} 
pensamiento de Kautsky. Los autores de la leyenda prueban, refiriéndose al periódico Nachalo, que Parvus es un peligroso emisario de la teoría de la revolución permanente. ${ }^{6}$

Eso es por supuesto sólo una broma ingeniosa. Una broma completamente estúpida, por otra parte, es el intento, dictado por pereza espiritual, de negar la competencia de Kautsky en cuestiones de la Revolución rusa. Es especialmente notable que tal intento fue a veces hecho precisamente por aquellos camaradas que se contentaron con la definición general de nuestra revolución como burguesa, y que la identificaban como cuestión de principio con las viejas revoluciones burguesas de Europa Occidental. Eso implicaría que los teóricos europeos de la Social Democracia son incapaces de captar el tradicional carácter burgués de la Revolución rusa porque es... demasiado peculiar para ser comprendida.

Pedimos disculpas a nuestros lectores por dedicar algunas líneas a esas necedades. El artículo de Kautsky es un fenómeno tan sobresaliente que debe ser considerado aparte de tales insignificancias anecdóticas.

\section{Kautsky sobre la revolución rusa León Trotsky (23 diciembre 1906) ${ }^{7}$}

[...] Para muchos camaradas [el artículo de Kautsky] parecerá completamente inesperado e incongruente, tal vez hasta sólo algún tipo de idea pasajera. Pero esta no es la primera vez que ha expresado tales pensamientos. La diferencia es que ahora él las ha reunido en respuesta a la consulta de Plejánov. En su trabajo del año pasado sobre el proletariado norteamericano, ${ }^{8}$ Kautsky ya proporcionó un breve pero significativo análisis de las relaciones de clase en la Revolución rusa, que ahora usa como base para el [presente] estudio [...]

Después de proporcionar un esquema general de las condiciones socio-históricas que explican, por una parte, la insignificancia política de la burguesía rusa, la ausencia de

\footnotetext{
${ }^{6}$ N. de los Ed.: Kautsky, que no leía ruso, obviamente no podría haber sido convertido a la teoría de la revolución permanente leyendo Nachalo.

${ }^{7}$ N. de los Ed.: Trotsky 1907. En pp. 122-39 Trotsky proporciona un sumario del ensayo de Kautsky a través de fragmentos detallados. Para el comentario de Trotsky ver: Richard Day and Daniel Gaido (eds.), Witnesses to Permanent Revolution: The documentary record, Leiden: Brill, 2009 pp. 139-48.

${ }^{8}$ N. de los Ed.: K. Kautsky, "The American Worker" (febrero de 1906), en Richard Day and Daniel Gaido (eds.), Witnesses to Permanent Revolution: The documentary record, Leiden: Brill, 2009, pp. 609-661.
} 
cualquier movimiento serio de democracia burguesa y por otra parte el poderío del proletariado revolucionario, Kautsky escribió lo siguiente:

La lucha por los intereses de toda Rusia recae en los hombros de la única clase moderna fuerte que posee: el proletariado industrial. De esta forma, los trabajadores rusos pueden ejercer una fuerte influencia política, y la lucha por la liberación de la tierra del asfixiante pulpo del absolutismo se ha convertido en un duelo entre el zar y la clase trabajadora; un duelo en el que los campesinos proveen una indispensable asistencia pero en el cual de ninguna manera tienen el rol dirigente. ${ }^{9}$

En cuanto a la perspectiva de la revolución mundial en conexión con la revolución en Rusia, en 1904 Kautsky escribió: “una revolución en Rusia (que en ese momento sólo se preveía) no puede establecer un régimen socialista inmediatamente. Las condiciones económicas del país no están lo suficientemente desarrolladas para eso". ${ }^{10}$ Pero la revolución rusa debe inevitablemente dar un impulso poderoso al movimiento proletario del resto de Europa, y el resultado de una lucha revitalizada en Alemania podría ser que el proletariado llegara al poder. “Tal resultado”, continúa Kautsky,

Tendrá inevitablemente un efecto poderoso sobre toda Europa y traerá con él la supremacía política del proletariado europeo, creando de este modo para el proletariado de Europa del Este la posibilidad de abreviar las etapas de su propio desarrollo e, imitando el ejemplo alemán, de crear artificialmente instituciones socialistas. Una sociedad no puede, como un todo, saltear las diferentes etapas de su desarrollo, pero esto puede ser hecho por sus elementos particulares, que pueden acelerar su propio desarrollo atrasado imitando a los países avanzados, y así ellos incluso pueden llegar a la vanguardia del desarrollo porque no están arrastrando el lastre de la tradición con la que un viejo país debe lidiar... Esto podría ocurrir [continúa Kautsky] pero, como ya hemos dicho, aquí abandonamos los dominios de la inevitabilidad y entramos a los de la posibilidad, lo que significa que todo puede también resultar bastante diferente. ${ }^{11}$

Esto fue escrito antes del estallido de la revolución rusa. Desde entonces, pasaron casi tres años. Y no importa cuán cuidadosamente habló Kautsky en la parte final del artículo anterior, es claro que en términos de perspectivas internacionales el curso de los eventos

\footnotetext{
${ }^{9}$ Ibid., p. 625

${ }^{10}$ N. de los Ed.: K. Kautsky, "Revolutionary Questions", en Richard Day and Daniel Gaido (eds.), Witnesses to Permanent Revolution: The documentary record, Leiden: Brill, 2009, p. 216. Trotsky omite la próxima oración de Kautsky: "Lo mejor que puede hacer [la revolución] es lograr un gobierno democrático detrás del cual estaría un proletariado fuerte, impetuoso y progresista que sea capaz de exigir concesiones importantes."

${ }^{11}$ N. de los Ed.: Kautsky 1906a. La traducción al ruso que cita Trotsky difiere levemente del original de Kautsky en alemán. Ver: Richard Day and Daniel Gaido (eds.), Witnesses to Permanent Revolution: The documentary record, Leiden: Brill, 2009, p. 219.
} 
durante esos años ha tomado la dirección que él caracterizó como "posibilidad” histórica. Pero ese no es el punto esencial. Si la Revolución rusa puede suscitar directamente una agitación socio-política en Europa, y justo ahora esto puede repercutir en el desarrollo y resultados de la revolución rusa, son cuestiones que, aunque importantes, por ahora sólo pueden ser respondidas provisionalmente. En el presente, el punto central se refiere a las relaciones internas y al curso posterior de la revolución rusa. Y en lo que se refiere a esta cuestión, la opinión de Kautsky no puede ser más clara. Debemos estar extremadamente agradecidos al camarada Plejánov, ya que su cuestionario provocó que un socialista minucioso y profundamente reflexivo hable tan categóricamente; todos debemos estar tanto más agradecidos porque la consulta dirigida a Kautsky fue tan ideológicamente imparcial y porque Plejánov debe haber sabido, por todo lo que Kautsky ha escrito previamente sobre la Revolución rusa, que la respuesta difícilmente podría dar algún apoyo a las opiniones actuales del propio Plejánov. ${ }^{12}$

Kautsky, quien muy raramente habla de materialismo dialectico pero siempre usa el método excelentemente al analizar las relaciones sociales, respondió la primera pregunta del camarada Plejánov rehusándose llamar burguesa a la revolución rusa. La época de las revoluciones burguesas ha pasado, y esto es también verdad para Rusia. No tenemos un movimiento democrático-burgués que sea independiente y revolucionario. Ni tendremos uno, porque falta la fundamental precondición socio-económica de tal movimiento, es decir, una poderosa clase media urbana, una pequeña burguesía con pasado histórico y también un histórico futuro. El campesinado representa una enorme fuente de energía revolucionaria, pero es incapaz de desempeñar un rol histórico independiente. El proletariado tendrá que guiar al campesinado y, en cierta medida, cumplir el mismo rol en relación a éste que aquel que desempeñó la pequeña burguesía de las ciudades en las revoluciones pasadas, en relación al proletariado. "La burguesía rusa cederá todas sus posiciones revolucionarias al proletariado. También deberá ceder hegemonía revolucionaria sobre los campesinos." ${ }^{13}$ Kautsky lleva su análisis hasta el momento en que un profundo antagonismo social se abre entre el proletariado en el poder y las capas influyentes de las masas campesinas en quienes el poder proletariado confía. ¿Cuál es la salida de este antagonismo?

No está completamente claro para mí lo que los camaradas de la mayoría ${ }^{14}$ quieren decir con la expresión "dictadura democrática del proletariado y el campesinado". No querría tergiversarlos describiendo incorrectamente el contenido de esta "dictadura" de coalición. Pero si quieren decir que la Social Democracia entra en una alianza formal con el

\footnotetext{
${ }^{12}$ N. de los Ed.: Para la interpretación subjetiva de Plejánov sobre la respuesta de Kautsky, ver Plejánov 1926a, pp. 295-7.

${ }^{13}$ L. Trotsky 1969, pp. 69-74

${ }^{14}$ N. de los Ed.: Los Bolcheviques, dirigidos por Lenin, propusieron la 'dictadura democrática del proletariado y el campesinado'.
} 
partido campesino para formar un gobierno, posiblemente uno en que el segundo es numéricamente predominante, y que ese gobierno entonces crea un régimen democrático, tras lo cual uno de los aliados, el proletariado, pacíficamente se transforma en oposición, entonces, en respuesta a tal opinión yo sólo puedo repetir lo que ya he escrito en mis Resultados y Perspectivas.

La dominación política del proletariado es incompatible con su esclavitud económica. Cualquiera sea la bandera política con la que el proletariado ha llegado al poder, será obligado a tomar el camino de la política socialista. Sería la mayor utopía pensar que el proletariado, habiendo sido elevado a la dominación política por el mecanismo interno de una revolución burguesa, será capaz incluso si así lo desea, de limitar su misión a la creación de condiciones democrático republicanas para la dominación social de la burguesía. La supremacía política del proletariado, incluso si es sólo temporaria, debilitará en grado extremo la resistencia del capital, que siempre requiere el apoyo del estado, y dará a la lucha económica del proletariado un tremendo alcance. Los trabajadores no pueden sino demandar apoyo para los huelguistas por parte del gobierno revolucionario, y un gobierno que dependa del proletariado no podrá rehusar tal apoyo. Pero esto significa paralizar el efecto del ejército de reserva de trabajadores y hacer a los trabajadores dominantes no sólo en el campo político, sino también en el económico, y convertir la propiedad privada de los medios de producción en una ficción. Estas inevitables consecuencias socio-económicas de la dictadura del proletariado ${ }^{15}$ se revelarán muy pronto, mucho antes que la democratización del sistema político se haya completado. ${ }^{16}[\ldots]$

Desde los primeros momentos después de la toma de poder, el proletariado deberá encontrar apoyos en los antagonismos entre los pobres de las aldeas y los ricos de éstas, entre el proletariado agrícola y la burguesía agraria. Mientras que la heterogeneidad del campesinado crea dificultades y estrecha las bases para una política proletaria, el insuficiente grado de diferenciación de clase creará obstáculos a la introducción dentro del campesinado de una lucha de clases desarrollada, en la cual el proletariado urbano pueda confiar. El primitivismo del campesinado muestra su cara hostil al proletariado.

La tibieza del campesinado, su pasividad política, y la cada vez mayor oposición activa de sus estratos superiores, no puede sino tener una influencia en una parte de los intelectuales y en la pequeña burguesía urbana.

De este modo, mientras más clara y determinada se haga la política del proletariado en el poder, más estrecha e inestable será la tierra bajo sus pies. ${ }^{17}[\ldots]$

\footnotetext{
15 N. del Original: Kautsky rechaza llamar esta dominación política del proletariado una dictadura, e igualmente normalmente evito usar esta palabra; en cualquier caso, mi comprensión del contenido social del gobierno proletario es el mismo que para Kautsky.

${ }^{16}$ L. Trotsky 1969, pp. 100-6

${ }^{17}$ L. Trotsky 1969, pp. 75-81
} 
Pero ¿hasta dónde puede ser aplicada la política socialista de la clase trabajadora en las condiciones económicas de Rusia? Podemos decir una cosa con certeza - que tendrá que lidiar con obstáculos políticos mucho antes de tropezarse con el atraso técnico del país. Sin el apoyo directo del proletariado europeo, la clase trabajadora de Rusia no podrá mantenerse en el poder y transformar su supremacía temporaria en una dictadura socialista duradera. ${ }^{18}$

Kautsky dice que los límites a la actividad del proletariado victorioso se encontrarán en los intereses sociales del campesinado, que apoya al régimen revolucionario. Pero esto, por supuesto, no debe ser entendido en el sentido de que el proletariado, en virtud de algún acuerdo expreso con sus aliados, no debe cruzar ciertos límites. La cuestión no se refiere a un acuerdo. Los “límites” que el proletariado va a encontrar serán puramente obstáculos externos y objetivos, que en algún momento de su gobierno no será capaz de superar. No hace falta decir que el proletariado en el poder hará todo lo posible para evitar un conflicto prematuro con el campesinado. Pero como la posesión del poder no cambiará la naturaleza de clase del proletariado - sin dudas, hará lo contrario y forzará a esa naturaleza a hacerse más visible - y como el proletariado apoyará a los trabajadores agrícolas en su lucha por una vida más digna, el resultado es que el conflicto entre el proletariado y el campesinado “fuerte”, en última instancia, será inevitable. Pero esto será el inicio del fin. ¿Cómo podría resolverse este conflicto? Por supuesto, no será resuelto teniendo representantes del proletariado que pasen de puestos ministeriales a los de la oposición. El asunto será mucho más complejo que eso. El conflicto terminará en guerra civil y en la derrota del proletariado. Dentro de los límites de una revolución nacional, y dadas nuestras condiciones sociales, no hay otra "salida” para la dominación política del proletariado. Por esto es que el proletariado va a enfrentar, desde el primer momento de su dominio, una tarea colosal con implicancias de vida o muerte, concretamente, traspasar los límites nacionales de la Revolución rusa y poner en movimiento todos los recursos de su poder temporario para transformar el levantamiento nacional en un episodio de la revolución europea. Este es el camino que surge de toda la situación revolucionaria como la describe Kautsky, y las líneas finales de su artículo apuntan exactamente a esa conclusión.

¿Cómo responde Kautsky a la segunda pregunta de Plejánov, sobre la adecuada relación con la democracia burguesa, “que está luchando a su manera por la libertad política”? Kautsky responde preguntando: ¿Qué queremos decir con democracia? El tipo de democracia revolucionaria que escribió su nombre en la historia no existe en Rusia. Todo lo que queda es liberalismo burgués por un lado, que es anti-revolucionario hasta la médula, y las masas populares por el otro, sobre todo, el campesinado. Esas son dos entidades completamente diferentes. El camarada Plejánov hace su pregunta en términos de una

\footnotetext{
${ }^{18}$ N. de los Ed.: Trotsky 1969, p. 105. Estas palabras enfatizan dramáticamente la diferencia entre dominación temporaria y una dictadura socialista.
} 
"fórmula algebraica" de la democracia burguesa. Esencialmente, esto significa que él piensa en términos de asimilación de los Cadetes con las masas populares. En realidad, no obstante, tal asimilación no ha ocurrido y, según Kautsky, no ocurrirá.

Para resolver la cuestión agraria, será necesario renunciar a todas las dudas y prejuicios liberales y adoptar una posición revolucionaria audaz. Sin embargo, esto nuevamente requiere encontrar apoyo en las ciudades, en los centros de la vida política. No hay tal apoyo aparte del proletariado y sólo un partido socialista puede confiar en el proletariado. Kautsky espera que concentremos nuestras tácticas en la lucha por la directa e inmediata influencia sobre el campesinado. ¿Podrá el liberalismo competir con nosotros en este ámbito? En el momento en que el campesinado surja en la forma del grupo Trudovik, ${ }^{19}$ los liberales serán completamente desalentados.

Mucho se ha escrito sobre el carácter difuso, la inestabilidad y la indecisión de los Trudoviks, y todo esto está fuera de discusión. Pero, ¿esto también altera el hecho extremadamente importante que el campesinado ruso, que acaba de ser despertado por el trueno de la revolución y ha sido llamado por primera vez para formular sus demandas, sin embargo envió diputados a la Duma que, en su mayor parte, resultaron ser patentados “demócratas" de izquierda de los zemstvos ${ }^{20}$, las universidades y los periodistas? Y ¿cuándo sucedió esto?: en un momento cuando [la Duma] todavía está privada de cualquier oportunidad de oír inquietudes expresadas libremente y todavía permanece confundida por los detalles de un complejo sistema electoral, en un momento cuando los que se llaman a sí mismos Demócratas Constitucionales estaban en el medio de su luna de miel con el pueblo.

Por supuesto, no tiene sentido idealizar a los Trudoviks, por cuanto ellos no son ciertamente la última palabra en la evolución política del campesinado. Pero eliminarlos despectivamente o amontonarlos junto a los Cadetes sería un grave error político. Por supuesto, el ala izquierda de los Cadetes tiene vínculos ocasionales con el campesinado, y en la determinación práctica de nuestra posición en las localidades debemos considerar esto. Pero como un todo, el campesinado no tiene vínculos con el liberalismo en general. Es difícil decir en qué medida los diputados campesinos en la segunda Duma realmente representarán al campesinado, y quiénes serán esos diputados, es difícil de predecir. No hay duda, sin embargo, que el campesinado se ha movido a la izquierda al mismo tiempo en que los Cadetes han doblado a la derecha. Kautsky habla de Social Democracia en términos de liderazgo revolucionario del campesinado. En ese sentido, simplemente describe la

\footnotetext{
${ }^{19}$ N. de los Ed.: En abril de 1906, un grupo de diputados campesinos en la Duma comenzaron a separarse de los Socialistas Revolucionarios para formar un partido independiente. El programa Trudovik apoyaba demandas campesinas de propiedad de la tierra y poner fin a todo vestigio de feudalismo. Los Trudoviks nunca se separaron totalmente de los Socialistas Revolucionarios, en cambio, vacilaron entre estos y los Social Demócratas como Trotsky predijo que harían.

${ }^{20}$ N. de los Ed.: los Zemstvos eran órganos de gobierno local, en cuya composición los nobles detentaban la abrumadora mayoría (74\%), aunque como cuerpos colegiados, sólo representaban al 1,3\% de la población. A pesar de esto, se transformaron en órganos de oposición al zarismo
} 
situación que ya existe en el Cáucaso. Guria $^{21}$ es el modelo terminado de relaciones revolucionarias entre el campesinado y el partido del proletariado.

En respuesta a la tercera pregunta, sobre las tácticas en las elecciones a la Duma, Kautsky contesta que "[la] acción conjunta con el liberalismo es sólo posible siempre y cuando no afecte la acción conjunta con el campesinado”. Esta cautelosa formulación es perfectamente apropiada. Permite limitados acuerdos prácticos con los Cadetes, sin tratarlos al mismo tiempo como centrales para la campaña electoral o lo que es más importante, considerarlos como el punto de partida para una campaña de coalición. He considerado en otra parte de este volumen la motivación política para los acuerdos electorales. Aquí voy a decir sólo que la motivación para acuerdos con los liberales queda completamente dentro de los límites de nuestra directa lucha contra el liberalismo por la influencia sobre las masas populares.

Repito: la cuestión ahora no es en qué etapa está nuestra revolución, sino más bien el camino por el cual se va a desarrollar. El asunto, por supuesto, no es cómo llamar a nuestra revolución - si es burguesa o socialista - el asunto real es establecer su dirección actual analizando las fuerzas involucradas. Mientras tanto, nosotros también frecuentemente reemplazamos un análisis materialista con una deducción formalista en el sentido de que nuestra revolución es una revolución burguesa; una revolución burguesa victoriosa transfiere el poder a la burguesía; el proletariado debe ayudar a la revolución burguesa a vencer; entonces, debe promover la transferencia de poder a la burguesía; la idea de un gobierno de los trabajadores es por lo tanto incompatible con las tácticas proletarias en la época de las revoluciones burguesas, etc., etc.

Tales series de silogismos escolásticos son sólo basura. La construcción puede ser elegante, pero uno debe tener cuidado que ninguna de las proposiciones presuponga "lo que tiene que ser probado”. Kautsky rechaza llamar a nuestra revolución burguesa porque la burguesía no es la fuerza dirigente, aunque podríamos provisionalmente aceptar esta designación en el sentido que nuestra revolución está todavía luchando para lograr las condiciones "normales” para la existencia de la sociedad burguesa. ¿Pero esto realmente responde a la pregunta de qué fuerzas están actualmente luchando por esas condiciones "normales” o sólo cómo ellas lo están haciendo? Sabemos que en un momento el ejemplo "plebeyo" de los victoriosos sans-culottes (según Marx) creó las condiciones para el dominio de la burguesía capitalista. ¿No hay razones para pensar que hoy esas condiciones serán preparadas por el ejemplo de clase del victorioso proletariado?

Mientras que los sans-culottes proporcionaron apoyo a los Jacobinos, el proletariado obviamente llevará a la Social Democracia al poder. El punto es que una definición general o, para ser más exactos, una etiqueta, no puede plantear o resolver tales problemas. Esto requiere análisis, y el análisis debe responder preguntas tales como: ¿Se está desarrollando

\footnotetext{
${ }^{21}$ N. de los Ed.: Un distrito histórico del oeste de Georgia.
} 
nuestra revolución? ¿Tiene alguna chance de victoria, es decir, de transferir el poder a una clase opositora? Si es así ¿a qué clase? ¿Qué partido es o podría convertirse en su representante político? Quienquiera que reconozca que la revolución tiene todas las posibilidades para la victoria decisiva, pero sin embargo niega simultáneamente la inevitabilidad o la probabilidad del dominio de la clase trabajadora, obviamente tiene en mente algún otro postulante al poder. ¿Dónde está este pretendiente y quién es? Obviamente, es la democracia burguesa. ¿¿De qué clases depende? ¿Dónde está su ejército de luchadores?

Ya que el proletariado ha sido hasta ahora la fuerza dirigente de la revolución, el tipo de ejército que podría asegurar a sus representantes una posición completamente independiente tendrá necesariamente que estar también opuesto a cualquier gobierno democrático burgués. La cuestión principal no es si la democracia burguesa en nuestro país ha o no cumplido este rol histórico (por supuesto que no lo ha hecho), el asunto real se refiere a los límites posibles de ese rol. Entre nosotros no hay Tercer Estado, lo que principalmente significa una pequeña burguesía fuerte, culta y revolucionaria. Este es un hecho fundamental. Entre nuestra población urbana, el proletariado urbano toma el lugar de los demócratas pequeño-burgueses. ¿Y quién reemplazará a los demócratas pequeñoburgueses en términos de poder? No he oído respuesta definitiva a esta cuestión, aunque ha sido discutida en la literatura de nuestro partido por casi dos años, desde el momento del prólogo de Parvus a mi panfleto Hasta el nueve de Enero.

Personalmente, con frecuencia he tenido que volver a esta pregunta. Si el lector se toma la molestia de considerar mi artículo 'Resultados y Perspectivas' (en Nuestra Revolución, pp. 224-86), ${ }^{22}$ entonces va a ver que no tengo motivo para rechazar alguna de las posiciones formuladas en el artículo de Kautsky que he traducido, porque el desarrollo de nuestro pensamiento en estos dos artículos es idéntico. Encuentro esta circunstancia de lo más gratificante ya que un crítico, una persona respetada por todos los tipos de marxistas, aunque también muy inclinado a expresar prejuicios comunes, recientemente rechazó mi trabajo con soberano desprecio con el argumento de que a pesar de mis nobles intenciones, yo había construido puras fantasías. No había más que decir porque el digno crítico no se tomó la molestia de pensar detenidamente en mi análisis. Aunque el artículo de Kautsky no introduce nada nuevo en términos de argumentación, parece que su trabajo es más apropiado y relevante. Por supuesto, esto no es porque escandalizó al exponente de los prejuicios comunes sino porque el autor, en el caso del artículo de Kautsky, tiene tal autoridad que obliga a los camaradas, incluso aquellos con un punto de vista diferente, a hablar más precisa y concretamente de las relaciones sociales involucradas en la revolución. Esto es exactamente lo que estoy esperando tan impacientemente escuchar. A

\footnotetext{
${ }^{22}$ N. de los Ed.: la referencia de páginas es de la edición rusa de Trotsky 1906, en la cual Resultados y Perspectivas fue publicado por primera vez.
} 
pesar de todas mis esperanzas [para tal explicación], hasta ahora no he podido aprender nada en este sentido de mis críticos.

\section{Prefacio a la traducción rusa de 'Fuerzas motrices y perspectivas de la revolución rusa’ de K. Kautsky. \\ V.I. Lenin \\ (Diciembre 1906)}

K. Kautsky es reconocido desde hace tiempo por los trabajadores progresistas de Rusia como su escritor, como un escritor que no sólo puede justificar y exponer la doctrina teórica del Marxismo revolucionario, sino que además aplicarla, con conocimiento en los asuntos y a través del análisis de los hechos, a las complejas e intrincadas cuestiones de la Revolución Rusa. Y ahora, cuando la atención de los socialdemócratas está a veces totalmente ocupada con el parloteo inútil de los Petrushkas ${ }^{23}$ liberales y de sus conscientes o inconscientes aduladores, cuando para mucha gente los tecnicismos del insignificante parlamentarismo ocultan los problemas fundamentales de la lucha de clases proletaria, y cuando el desánimo frecuentemente abruma incluso a la gente decente y daña sus facultades intelectuales y políticas; es ahora sumamente importante para todos los socialdemócratas de Rusia prestar cuidadosa atención a la opinión de Kautsky sobre los problemas fundamentales de la revolución rusa. Y no tanto sólo prestar atención a la opinión de Kautsky, como también reflexionar sobre la manera en que plantea la cuestión, porque Kautsky no es tan superficial para explayarse sobre asuntos específicos de la táctica rusa con la cual no está suficientemente familiarizado, ni es tan ignorante de las cuestiones rusas para descartarlas con comentarios triviales o con una repetición irreflexiva de las últimas declaraciones de moda.

Kautsky está respondiendo a las preguntas que Plejánov formuló a un grupo de socialistas extranjeros $\mathrm{y}$, en la respuesta a estas preguntas, o más concretamente, al seleccionar de esas preguntas tan pobremente formuladas, los puntos que pueden ser temas útiles para la discusión entre los socialistas de todos los países, Kautsky comienza con una modesta reserva: "Me siento como un novato frente a mis camaradas rusos cuando se trata de los asuntos rusos." Esto no es falsa modestia de un "general” socialdemócrata que comienza con los modales afectados de un pequeño burgués y termina con la arrogancia de un Borbón. Para nada, Kautsky, de hecho se ha limitado a contestar sólo aquellas preguntas a través de un análisis por el que puede ayudar al pensamiento de los socialdemócratas de

\footnotetext{
${ }^{23}$ N. de los Ed.: Petrushka es un criado de Almas Muertas de Gogol que leía libros pronunciando cada palabra sin tener en cuenta su significado.
} 
Rusia a resolver por sí mismos las tareas concretas y las consignas del día. Kautsky se negó a ser un general impartiendo órdenes: “¡Media vuelta a la derecha!” o “¡Media vuelta a la izquierda!”. Él ha preferido preservar su posición como camarada manteniéndose a la distancia, pero como un camarada atento, señalando dónde debemos buscar la respuesta por nosotros mismos.

Plejánov preguntó a Kautsky: 1. ¿Cuál es el “carácter general” de la Revolución Rusa: burgués o socialista? 2. ¿Cuál debería ser la actitud de los socialdemócratas hacia los demócratas burgueses? 3. ¿Deberían los socialdemócratas apoyar a los partidos de la oposición en las elecciones a la Duma?

A simple vista estas cuestiones parecen haber sido elegidas con mucha delicadeza. Pero, como dice el refrán, "Si una cosa es muy delicada, se rompe.” De hecho, cualquier persona más o menos competente y observadora verá inmediatamente el delicado... subterfugio en estas preguntas. Subterfugio, primero, porque es un ejemplo típico de la metafísica contra la cual Plejánov tiene tanto gusto de declamar pomposamente, aunque él no pueda mantenerla fuera de sus propios juicios históricos concretos. Subterfugio, segundo, porque la persona consultada es artificialmente conducida hacia un pequeño y excesivamente angosto rincón. Sólo aquellos que son completamente inocentes, o incluso podría decir virginales, en cuestiones de política pueden no darse cuenta que Plejánov deliberadamente comienza desde una posición muy por encima del tema y delicadamente empuja a la persona que está consultando en la posición de justificar... ¡una coalición con los Cadetes! ${ }^{24}$

Guiar a un interlocutor ingenuo a justificar bloques con cierto partido, sin nombrar a ese partido; hablar de un movimiento revolucionario sin distinguir a los demócratas revolucionarios de la oposición demócrata burguesa; insinuar que la burguesía está "luchando" a su manera, esto es, de una forma distinta de la del proletariado, sin decir lisa y llanamente cuál es la diferencia; entrampar al interlocutor como un pichón con la carnada de la resolución de Amsterdam ${ }^{25}$, con el fin de ocultar a los extranjeros la real manzana de la discordia entre los socialdemócratas rusos; manifestar reglas concretas relacionadas a tácticas específicas en casos específicos y la actitud a adoptarse hacia los variados partidos de los demócratas burgueses, a partir de una frase general sobre el carácter general de la revolución, en lugar de deducir este “carácter general de la Revolución Rusa” del análisis

\footnotetext{
${ }^{24}$ N. de los Ed.: El Partido Democrático Constitucional (cuyos miembros eran conocidos como Cadetes) era una agrupación liberal radical formada en Octubre de 1905 con el objetivo de participar en las elecciones para la Primera Duma en la cual surgieron como el partido mayoritario.

${ }^{25}$ N. de los Ed.: En el Congreso de Amsterdam de la Segunda Internacional en Agosto de 1904, el SPD y los Marxistas Franceses se combinaron para proponer una denuncia expresa al revisionismo y a la participación socialista en los gobiernos burgueses. Plejánov invocó la autoridad de esta resolución, que remarcaba en su Art. 2 que "La Social Democracia no puede luchar para participar en el gobierno bajo la sociedad burguesa [...]." contra los proyectos de los Bolcheviques y partidarios de la estrategia de la revolución permanente (De Leon 1904, pp. 132-3).
} 
preciso de los datos concretos sobre los intereses y posiciones de las diferentes clases en la Revolución rusa: ¿no es todo esto un subterfugio? ¿No es abiertamente una burla al materialismo dialéctico de Marx?

"Digan sí cuando es sí, y no cuando es no; cualquier otra cosa que se le añada, viene del demonio" O una revolución burguesa o una socialista; jel resto puede ser "deducido" a partir de la "solución" principal por medio de simples silogismos!

Kautsky realiza una gran tarea al contestar tales preguntas, él capta el punto inmediatamente y va a la raíz del error contenido en la forma misma en que fueron formuladas. En rigor, Kautsky responde a las preguntas de Plejánov ¡rechazando la formulación de éstas hecha por Plejánov! Kautsky responde a Plejánov corrigiendo la formulación de las preguntas de Plejánov. Mientras más suave y cautelosamente él corrige al interrogador, más implacable es su crítica a la formulación de las preguntas de Plejánov. "Haríamos bien”, escribe Kautsky, "en darnos cuenta que nos estamos moviendo hacia situaciones completamente nuevas y hacia problemas para los cuales ninguno de los viejos modelos es adecuado".

Esto da en el clavo respecto a la pregunta de Plejánov: ¿es nuestra revolución burguesa o socialista en su carácter general? Kautsky dice que esto es el modelo viejo. La pregunta no debe ser expresada de esa manera, no es la manera Marxista. La revolución en Rusia no es una revolución burguesa porque la burguesía no es una de las fuerzas motrices del presente movimiento revolucionario en Rusia. Y la revolución en Rusia no es una revolución socialista porque de ninguna manera puede conducir al proletariado hacia un gobierno exclusivo o a la dictadura. La Socialdemocracia es capaz de vencer en la Revolución Rusa y debe esforzarse para lograrlo. Pero la victoria en la presente revolución no puede ser la victoria del proletariado solo, sin la ayuda de otras clases. ¿Qué clase entonces, frente a las condiciones objetivas de la presente revolución, es la aliada del proletariado? El campesinado: "un sustancial interés común para todo el período de la lucha revolucionaria existe sin embargo, sólo entre el proletariado y el campesinado".

Todas estas proposiciones de Kautsky son una brillante confirmación de la táctica del ala revolucionaria de la Socialdemocracia rusa, esto es, la táctica de los Bolcheviques. Esta confirmación es muy valiosa porque Kautsky, separando cuestiones concretas y prácticas, ha concentrado toda su atención en una exposición sistemática de los principios generales de la táctica socialista en nuestra revolución. Ha demostrado que el trillado razonamiento de Plejánov del argumento "la revolución es una revolución burguesa; luego, debemos apoyar a la burguesía” no tiene nada en común con el Marxismo. Él, de esa manera reconoce el error principal de nuestro oportunismo socialdemócrata, es decir, menchevismo, contra el que los bolcheviques vienen combatiendo desde principios de 1905.

Además, el análisis de Kautsky, que no proviene de frases generales sino de un análisis de la situación e intereses de clases determinadas, reafirma la conclusión, que los 
aduladores de los Cadetes dentro de nuestras filas consideraron "poco diplomática”, concretamente: que la burguesía en Rusia teme a la revolución más que a la reacción; que desprecia a la reacción porque engendra la revolución; que quiere libertad política para frenar la revolución. Comparar esto con la fe ingenua en los Cadetes que profesa nuestro Plejánov quien, en sus preguntas, ¡equipara imperceptiblemente la lucha de la oposición contra el viejo régimen a la lucha contra los intentos del gobierno para aplastar el movimiento revolucionario! A diferencia de los Mencheviques, con sus opiniones estereotipadas sobre la “democracia burguesa”, Kautsky ha mostrado sus elementos revolucionarios y no revolucionarios, ha demostrado la bancarrota del liberalismo y mostró que, a medida en que los campesinos se hagan más independientes y más conscientes, los liberales inevitablemente girarán rápido hacia la derecha. Una revolución burguesa, llevada a cabo por el proletariado y el campesinado, a pesar de la inestabilidad de la burguesía, este principio fundamental de las tácticas Bolcheviques, es completamente confirmado por Kautsky.

Kautsky demuestra que en el curso de la revolución es bastante posible que el Partido Socialdemócrata conquiste la victoria y que ese partido debe inspirar a sus militantes la confianza en la victoria. La conclusión de Kautsky contradice completamente el miedo menchevique a una victoria socialdemócrata en la presente revolución. Los esfuerzos ridículos de Plejánov para “amoldar” las tareas de nuestra revolución “para que encajen en la resolución de Amsterdam” parecen peculiarmente cómicos cuando se los compara con la proposición simple y clara de Kautsky de que “es imposible luchar con éxito si uno renuncia de antemano a la victoria”.

La diferencia básica entre los métodos de Kautsky y aquellos del líder de nuestros actuales oportunistas, Plejánov, es mucho más llamativa cuando el primero declara: pensar que "todas las clases y partidos que están luchando por la libertad política tienen simplemente que trabajar juntas para obtenerla” significa "ver solamente la superficie política de los eventos". Esto suena como si Kautsky se estuviera refiriendo directamente a la pequeña banda de Socialdemócratas que desertaron a los liberales: los señores Portugálov, Prokopóvich, Kuskova, Bogucharsky, Izgoév, Struve y otros, que están cometiendo precisamente el error al que Kautsky se refiere (y quienes en el proceso están arrastrando a Plejánov con ellos). El hecho que Kautsky no esté familiarizado con los escritos de esos señores, sólo refuerza la importancia de su conclusión teórica.

Es innecesario decir que Kautsky está en completo acuerdo con las tesis fundamentales de todos los Socialdemócratas Rusos por las que el movimiento campesino es no-socialista, que el socialismo no puede surgir de la pequeña producción campesina, etc. Sería muy instructivo para los Socialistas Revolucionarios, a quienes les gusta afirmar que ellos “también coinciden con Marx”, considerar esas palabras de Kautsky. 
En conclusión, unas pocas palabras sobre 'autoridades'. Los Marxistas no pueden adoptar el punto de vista usual de los intelectuales radicales, con su abstracción pseudorevolucionaria: "nada de autoridades".

No; la clase obrera, que en todo el mundo está librando una dura y persistente lucha por una completa emancipación, necesita autoridades pero, por supuesto, sólo en el mismo sentido en que los jóvenes trabajadores necesitan la experiencia de los combatientes veteranos contra la opresión y la explotación, de hombres que han organizado numerosas huelgas, han participado en varias revoluciones, que están versados en las tradiciones revolucionarias y que tienen un amplio panorama político. El proletariado de cada país necesita la autoridad de la lucha mundial del proletariado. Necesitamos la autoridad de los teóricos de la socialdemocracia internacional para permitirnos comprender correctamente el programa y la táctica de nuestro partido. Pero esta autoridad naturalmente nada tiene en común con las autoridades oficiales de la ciencia burguesa y la política policíaca. Es la autoridad de la experiencia obtenida en la más diversificada lucha librada en las filas del ejército socialista internacional. Aunque esta autoridad es importante para ampliar el horizonte de aquellos involucrados en la lucha, sería inadmisible en el partido de los trabajadores, afirmar que las cuestiones prácticas y concretas de su política inmediata puedan ser resueltas por éstos desde afuera, manteniéndose lejos. El espíritu colectivo de los trabajadores con conciencia de clase, directamente involucrados en la lucha en cada país siempre será la autoridad suprema en todas estas cuestiones.

Este es nuestro punto de vista sobre la autoridad de las opiniones sostenidas por Kautsky y Plejánov. Los trabajos teóricos de éste último - principalmente su crítica a los Naródniki y a los oportunistas - conservan un valor duradero para la Socialdemocracia de toda Rusia y ningún “faccionalismo” podrá cegar a cualquier hombre que posea una mínima parte de "capacidad mental” en tal medida que pueda olvidar o negar la importancia de esto. Pero, como líder político de los Socialdemócratas rusos en la revolución burguesa de Rusia, como un táctico, Plejánov no resiste la crítica. En este ámbito él ha mostrado un oportunismo que es cien veces más dañino que el oportunismo de Bernstein hacia los trabajadores alemanes. Debemos luchar implacablemente contra esta política afín a los Cadetes de Plejánov, que ha vuelto al redil de Prokopovich ${ }^{26}$ y compañía, a quienes él mismo expulsó del Partido Socialdemócrata en 1899-1900.

Que este oportunismo táctico de Plejánov es una completa negación de los fundamentos del método Marxista es demostrado de la mejor manera por el argumento desarrollado por Kautsky en el ensayo aquí presentado al lector.

\footnotetext{
${ }^{26}$ N. de los. Ed.: Prokopovich, en un momento líder de la joven oposición del Grupo de Emancipación del Trabajo, había, para esta época, surgido como publicista de los Cadetes.
} 


\section{Fuerzas motrices y perspectivas de la revolución rusa. \\ Karl Kautsky}

(1905)

\section{La cuestión agraria y los liberales.}

La revolución rusa puede ser vista de dos maneras: como un movimiento para el derrocamiento del absolutismo y como el despertar de la enorme masa del pueblo ruso a la actividad política independiente. Lo primero sólo raspa la superficie de los eventos: desde este punto de vista parece tan lejano como si la revolución hubiera fallado. Pero sólo podemos hablar de un fracaso real si el movimiento encalla cuando se lo ve también desde la segunda perspectiva. Si se hace retroceder al pueblo ruso nuevamente hacia su vieja indiferencia política, entonces el absolutismo ciertamente habrá ganado y la revolución habrá perdido el juego. Pero, si eso no sucede, entonces la victoria de la revolución está asegurada, incluso si el absolutismo intenta prolongar por un tiempo la ilusión de su dominio, asesinando a su propia gente, derrochando su propia riqueza y devastando su propio país.

La masa del pueblo ruso está constituida, sin embargo, de campesinos. Lo que les preocupa es la cuestión agraria. Por lo tanto, esta cuestión tiene un lugar cada vez más destacado: el destino de la revolución depende de su resolución. Este es el caso, al menos, de la masa de Rusia específicamente, que es lo que estamos tratando aquí, pero no tal vez para Polonia, Finlandia o el Cáucaso.

Los campesinos en Rusia no son sólo la enorme mayoría de la población: todo el edificio de la economía y el estado descansa sobre la agricultura. Si la agricultura fuera a colapsar, también lo haría todo este edificio. De los observadores burgueses de Europa Occidental sobre la situación revolucionaria en Rusia, Martin ha reconocido esto claramente en su trabajo sobre el futuro de Rusia y es en esta premisa donde reside la certeza de su profecía sobre la bancarrota del estado ruso, la profecía que recientemente ha causado tal sensación en Alemania, aunque sólo en círculos burgueses que no sabían nada de la crítica socialista a la política económica de Rusia ${ }^{27}$

Los campesinos deben ser satisfechos y la agricultura puesta en sólidas bases económicas: estas son las condiciones que deben cumplirse antes que la población de Rusia vuelva a la pasividad y abandone la vía revolucionaria.

Casi todos los partidos en Rusia reconocen esto ahora. Pero difieren considerablemente en la manera en que ayudarían a los campesinos. Un ensayo publicado

\footnotetext{
${ }^{27}$ Nota del original: Rudolf Martin, Die Zukunft Russlands, Leipzig: Dieterich, 1906.
} 
recientemente, Sobre el Movimiento Agrario en Rusia ${ }^{28}$, dará al lector alemán una muy buena explicación sobre la actitud de los liberales: contiene traducciones de dos artículos rusos, uno de Petrunkevich, el reconocido político 'Cadete', y uno del profesor moscovita A. A. Manuilov, así como una colección de programas agrarios de los diferentes partidos rusos.

Como todos, los liberales admiten el atraso y la decadencia de la agricultura rusa. Manuilov escribe:

Nuestras mayores cosechas parecen tener la mitad del tamaño de las cosechas promedio en otros países. Si tomamos el rendimiento promedio de todas las variedades de grano en Rusia como 100, el rendimiento en otros países será: centeno 230, trigo 280, avena 277, etc. El rendimiento neto de cereales y papa para el área cultivable promedio del campesino ruso (0,74 desiatina) da en promedio 20,4 puds ${ }^{29}$, mientras que en otros países un área similar produciría 56,9 puds, específicamente en Bélgica 88, en el Reino Unido 84,4, en Japón 82,8 puds, etc....

El Profesor A.I. Chuprov también ha demostrado que las cosechas en nuestras tierras campesinas con sus 35-40 puds de centeno por desiatina son tan bajas que incluso las mejoras más primitivas, disponibles para todos, serían suficientes para elevar el rendimiento por encima de un 50\% del nivel actual. [Numerosos estudios de agrónomos sugieren que una sola y mejorada variedad de semilla sería casi suficiente para lograr este resultado] Pero la tecnología dispone de recursos incomparablemente más poderosos. Un rendimiento de 30 centenas métricas ${ }^{30}$ de centeno por hectárea o 200 puds por desiatina, es considerado bastante bajo en países con tecnología desarrollada. $^{31}$

Y las cosas están cada vez peor, no mejor. Manuilov prosigue:

En la actualidad, como el Departamento de Agricultura ha señalado en su informe, los campesinos tienen la cantidad mínima posible de ganado necesario para la existencia de la agricultura... En las cincuenta provincias de la Rusia Europea, el número de caballos en los diez años de 1888 a 1898

\footnotetext{
${ }^{28}$ Nota del original: 'Zur agrarbewegung in Russland’ (Teutonia-Verlag, Leipzig, 1905) Estos ensayos son incluídos en la colección rusa Agrarnyi Vopros, eds. P.D. Dolgorukov y I.I. Petrunkevich (2 vols., Moscú, 1905).

${ }^{29}$ Nota del original: 'Una desiatina es poco más que una hectárea y un pot poco más que 16 kilogramos’. N. de los Ed.: En el sistema métrico, 1,093 Ha y 16,38 Kg, en el sistema de medidas imperial británico, 2,7 acres y 36 libras.

${ }^{30}$ N. de los Ed.: La centena o hundredweight es una unidad de medida de masa del sistema anglosajón, que en el Reino Unido equivalía a 112 libras avoirdupois, es decir, 50,8 kilogramos del sistema métrico.

${ }^{31}$ Nota del original: A.A. Manuilov, en P.D. Dolgorukov y P.P. Petrunkevich, Agrarnyi Vopros, I, p. 61.
} 
cayó de 19.6 millones a 17 millones, y el ganado bovino de 34.6 millones a 24.5 millones... Comités locales han proporcionado evidencia que respalda de lo que he dicho en sus Transacciones. Parece, por ejemplo, que en la provincia de Nizhny Novgorod, la provisión de abono equivale a un quinto y un tercio de la demanda y, como resultado, el rendimiento promedio, independientemente del hecho que el suelo sea adecuado, es extremadamente bajo: 38 medidas de centeno y 49 medidas de avena. En el distrito Mikhailov de la provincia de Ryazan, sólo de una décima a una octava parte de la superficie es abonada. En el distrito de Klin de la provincia de Moscú, el abono es hecho dos veces y media por debajo del nivel normal. ${ }^{32}$

Liberales y socialistas están completamente de acuerdo al reconocer la importancia de estos hechos. Pero la tibieza liberal se hace inmediatamente evidente al momento de poner de manifiesto las razones de esos fenómenos y proponer los medios para solucionarlos. Su tibieza en el último caso surge de su posición de clase, pero forzosamente genera una similar tibieza en el primer caso. Un hombre que no está decidido a arrancar el mal de raíz por medios radicales, también debe estar asustado de dejar al descubierto sus raíces más profundas.

Los liberales ven las causas de la decadencia de la agricultura rusa en la forma en que los siervos fueron emancipados en 1861. Los campesinos fueron entonces desposeídos de una parte de sus tierras: no recibieron suficiente y lo que recibieron fue mayormente tierra mala. Si su parte en aquel momento era inadecuada, desde entonces se ha disminuido aún más porque la población ha crecido considerablemente. Sobre esto Manuilov escribe:

En 1860 la población rural consistía en 50 millones de almas de ambos sexos, pero al final de 1900 había llegado cerca de los 86 millones [...] Al mismo tiempo el tamaño promedio de la parcela fue reducido. De acuerdo a cifras producidas por la Comisión de Investigación sobre el empobrecimiento del Centro [de Rusia], la parcela promedio de un siervo emancipado en 1860 era equivalente a 4.8 desiatinas; en 1880, la extensión promedio de la parcela para un hombre se había reducido a 3.5, y en 1900 a 2.6 desiatinas. ${ }^{33}$

Los hechos citados aquí son verdades, pero para entender las causas de la decadencia en la agricultura, son sólo verdades a medias.

\footnotetext{
${ }^{32}$ Nota del original: A.A. Manuilov, en P.D. Dolgorukov y P.P. Petrunkevich, Agrarnyi Vopros, I, p. 63.

33 Nota del original: A.A. Manuilov, en P.D. Dolgorukov y P.P. Petrunkevich, Agrarnyi Vopros, I, p. 51.
} 
Cuando el yugo feudal fue levantado los campesinos de otros lugares fueron tratados de la misma manera que en Rusia y fueron despojados de su propiedad. En otros estados esto condujo frecuentemente al colapso de las explotaciones agrícolas, pero nunca llevó a la decadencia de la agricultura, a un deterioro de las explotaciones en general, a un incremento de malas cosechas. Al contrario, la pauperización de los campesinos creó el proletariado rural cuya existencia en ese estadio particular de la producción de mercancías constituyó una de las precondiciones de la agricultura capitalista basada en el trabajo asalariado. Esta pauperización condujo a una situación en la cual una parte del campesinado descendió al proletariado, mientras que otra parte alcanzó la prosperidad a costa de los jornaleros. De las ruinas de la destrozada economía campesina surge un nuevo y superior modo de producción. Pero en el caso de Rusia, sólo los comienzos de todo esto son discernibles. ¿Por qué sucedió esto? Esta es la pregunta decisiva.

No hay manera en que podamos acusar al comunismo aldeano de haber hecho imposible el advenimiento de la agricultura capitalista. El comunismo aldeano rápidamente cayó en decadencia y no tuvo la fuerza necesaria para evitar el surgimiento entre los aldeanos de proletarios sin tierras por una parte y especuladores por otra, o el desarrollo de relaciones de explotación capitalista de muchos tipos atroces. Por esta razón el comunismo aldeano actualmente en Rusia dejó de ser un verdadero baluarte contra el crecimiento de los métodos capitalistas en la agricultura.

Todas las condiciones del capitalismo ya existían, excepto por dos, pero estas eran las dos más importantes: la población campesina no había tenido hasta ahora la necesaria instrucción, la capacidad, para vencer los límites de la tradición y elegir con certeza, entre todas las cosas nuevas que estaban presionando aquellas que eran las más adecuadas y eficaces. Esto requiere una serie de conocimientos y métodos que son imposibles de adquirir sin una buena educación escolar. Pero el capital en sí, el dinero necesario, tampoco estaba a mano. Por lo tanto, las dos condiciones que tienen la mayor importancia para el desarrollo de la producción capitalista estaban ausentes. Precisamente el último factor, la acumulación de sumas de dinero suficientes en manos individuales, es el más indispensable de todos para que se desarrollen sobre la base de la producción de mercancías, formas de producción superiores y la aplicación de la ciencia a la producción.

Junto con la falta de instrucción está la falta de capital que es el factor decisivo en la crisis agrícola de Rusia. La escasez de tierras explica por qué los campesinos están empobrecidos, pero no explica por qué los campesinos sin embargo, siguen adelante en condiciones cada vez más miserables, por qué una clase de agricultores prósperos no surge para reemplazarlos, una clase que pueda adquirir las empobrecidas granjas campesinas y los administre racionalmente con recursos adecuados; por qué también la mayoría de las explotaciones mayores son también administrados irracionalmente y sin el capital suficiente y no desplazan a las tenencias campesinas arruinadas.

¿Por qué sucede esto? Esta pregunta debe ser contestada. 


\section{La escasez de capital en Rusia.}

La pregunta sobre las razones del atraso económico e intelectual de Rusia no puede ser contestada simplemente haciendo referencia al hecho de que el modo de producción moderno tuvo su origen en Europa Occidental y sólo está expandiéndose lentamente hacia el Este. Esto es porque inmediatamente se plantea la cuestión adicional de por qué se expande tan lentamente hacia el Este. En el momento en que Rusia estaba entrando en un contacto más cercano con Europa Occidental su agricultura estaba casi al mismo nivel en que está hoy y el Imperio estaba lleno de numerosos trabajadores campesinos. Norteamérica, por otra parte, era entonces una tierra virgen donde estaban perdidas unas pocas tribus de salvajes y bárbaros. A pesar de esto se ha convertido en el mayor poder capitalista del mundo.

Las razones para esta diferencia son múltiples, pero todas derivan del contraste entre la organización política de cada país. Norteamérica fue colonizada por granjeros y pequeños burgueses que encabezaron la lucha por la democracia contra el ascenso del absolutismo en Europa y quienes prefirieron libertad en la América salvaje a sometimiento al estado absoluto en la civilización europea. Rusia era una masa de innumerables comunidades aldeanas que estaban sólo preocupadas por sus asuntos propios y satisfechas con la democracia en su propia comunidad y que tenían sólo una vaga concepción del poder del estado y pasivamente lo dejaban a los gobernantes absolutos cuyos ejércitos las liberaron de los Mongoles y estaban obligados a protegerlas contra cualquier enemigo externo.

En Norteamérica había libertad política ilimitada que dio a los individuos absoluta libertad de acción. La necesidad de aceptar, y dominar las condiciones completamente nuevas requirió de los colonos que vinieron de Europa una enorme cantidad de esfuerzo individual, espiritual y físico, completa libertad de acción, extrema crueldad y la superación de innumerables prejuicios.

En Rusia por siglos no ha habido ni un rastro de libertad política; cada uno de los movimientos fuera de la comunidad aldeana estaba sujeto a supervisión policial. Más aún: existía sólo un muy limitado deseo de libertad de movimientos. Ha habido un "saludable

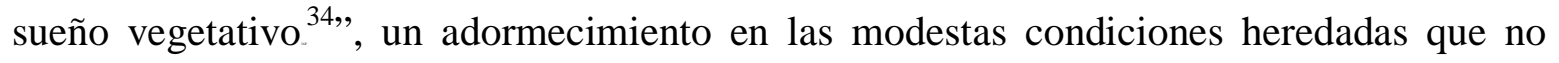
cambiaron por generaciones y que permitió crecer y arraigarse a todo tipo de prejuicios y paralizó todas las formas de energía.

\footnotetext{
${ }^{34}$ N. de los Ed.: En alemán gesunder Planzenschlaf, es una frase de Menzel con la que responde a la queja de Börne de que los alemanes estaban dormidos. Menzel replica que el sueño era saludable, por lo tanto preferible, para la evolución pacífica de Alemania antes que una revolución.
} 
Mientras que las condiciones para la población europea de Norteamérica engendraron todas las características espirituales que dan al hombre la ventaja en el modo de producción capitalista, las condiciones en Rusia engendraron precisamente esas características que hacen que los cautivos de la competencia capitalista sucumban y eso obstaculiza el desarrollo capitalista.

Además, desde Pedro el Grande, Rusia ha adherido a una política cuyos resultados ya me he referido en mi serie de artículos sobre el obrero norteamericano en el capítulo que se ocupa del capitalismo ruso. ${ }^{35}$ Sólo puedo reiterar aquí lo que dije allá.

Pedro I abrió Rusia a la civilización europea, es decir, al capitalismo, pero también condujo a Rusia dentro de las filas de las Grandes Potencias Europeas, la involucró en sus conflictos, la forzó a competir con ellas en armamentos militares en mar y tierra y medirse contra ellas en términos militares. Esto ocurrió cuando el capitalismo ya era muy fuerte en Europa Occidental y las fuerzas productivas estaban bien desarrolladas. A pesar de esto, incluso en Europa Occidental la rivalidad militar condujo a una serie de poderes a la bancarrota, por ejemplo, España y Portugal, y obstaculizó el desarrollo económico de muchos otros, a excepción de Inglaterra, que estaba resguardada por su posición insular de la necesidad de agotarse en guerras continentales, y pudo dedicar todos sus recursos a la armada por la cual regía los mares, hizo pingües ganancias de la piratería, la trata de esclavos, el contrabando y el saqueo de la India, y de este modo hizo de la guerra un negocio altamente rentable, un medio de acumular capital, como las Guerras Revolucionarias más tarde lo hicieron para Francia permitiendo a los victoriosos ejércitos de la República y el Imperio saquear a los países más ricos del continente Europeo, Bélgica, Holanda e Italia, y extraer un abundante botín también de otros países.

Rusia nunca ha emprendido guerras tan rentables. Ha habido un conjunto de serios obstáculos a su desarrollo como potencia naval, pero en la tierra limita sólo con vecinos pobres. Ha tenido éxito en derrotar a Japón y aprovechando las riquezas de China, hubiera, por primera vez en la historia desde su surgimiento como Gran Potencia Europea, sido capaz de sacar un beneficio económico considerable de una guerra. Pero la ironía de la historia quiso que sea precisamente esa guerra la que selló su bancarrota.

Como Rusia era, en términos económicos, la más débil y atrasada de las Grandes Potencias Europeas, el zarismo desde el siglo dieciocho, ha tenido que, para mantener su posición entre ellas, saquear a su propio pobre pueblo de manera creciente y haciendo imposible para ellos acumular riqueza alguna. La deuda estatal pronto se unió al militarismo para que este saqueo pudiera incrementarse.

No hay país en el mundo, ni siquiera los más ricos, en donde la rentabilidad de los impuestos sea suficiente para cubrir los enormes gastos que el militarismo de vez en cuando

${ }^{35}$ K. Kautsky “The American Worker” 1906, en: Richard Day and Daniel Gaido (eds.), Witnesses to Permanent Revolution: The documentary record, Leiden: Brill, 2009, pp. 609-61. 
requiere y que es colosal en tiempos de guerra pero aún considerables en períodos de armamento, rearme y otros por el estilo. En tales casos la deuda pública ha sido por mucho tiempo la forma de probada eficacia para producir recursos inmediatos para esos enormes gastos. El pago de los intereses de la deuda pública siempre es una pesada carga para la población que paga impuestos pero puede ser un medio de enriquecer a la clase capitalista de un país cuando ésta es acreedora del estado. El estado entonces expropia a la clase trabajadora, para enriquecer a la clase capitalista, multiplica su riqueza y simultáneamente aumenta el número de proletarios a su disposición.

Pero en Rusia no había ninguna clase capitalista capaz de cubrir los requerimientos de capital del estado y la presión impositiva constante hizo mucho más difícil para tal clase capitalista emerger en una escala suficiente. De este modo, el dinero tuvo que pedirse prestado principalmente a capitalistas extranjeros que fueron convocados para llenar las arcas del estado que habían sido vaciadas por la insaciable sed del militarismo. Estos desembolsos de capital no fueron utilizados productivamente: fueron usados sólo para jugar a los soldaditos y para el esplendor de la corte. El interés en ellos fluyó al extranjero y, junto con el militarismo, este interés pronto formó una segunda herida abierta, siempre ensanchándose, drenando la savia vital de Rusia.

La guerra de Crimea y sus consecuencias hicieron entender al gobierno ruso después de 1860 el hecho de el coloso de su poder descansaba sobre pies de barro, porque el despliegue de poder diplomático y militar es imposible a largo plazo sin poder económico. Pero, este poder económico surge en la sociedad moderna ante todo de la industria capitalista y en menor medida de la agricultura y sin duda no procede de una agricultura primitiva y empobrecida; es por eso que el absolutismo ruso aprovechó la idea de cerrar la brecha lo más rápido posible. Intentó crear industrias capitalistas a gran escala garantizando una enérgica ayuda estatal. Pero como el estado vivía de la agricultura, esto simplemente significó que la industria debía ser respaldada por la imposición de una carga más pesada sobre la población campesina. Así pues, la política de industrialización en tiempos de paz se convirtió, como la política de conquista en tiempos de guerra, en un medio para saquear y oprimir a los granjeros y sobre todo a los campesinos.

Esta política de tiempos de paz llevó, como la política de guerra lo hizo, a un creciente endeudamiento hacia los extranjeros. El crecimiento del capital doméstico progresó muy lentamente para los propósitos del gobierno ruso; quería lograr una rápida independencia de los países extranjeros en aquellas ramas de la industria que son importantes para los armamentos militares, que producen cañones y armas, barcos y ferrocarriles y que proveen equipamiento. Como el capital interno estaba creciendo muy lentamente para fundar las empresas a gran escala necesarias, el gobierno en décadas recientes ha tratado cada vez más de atraer capital extranjero y éste está en particular, fuertemente representado en las industrias del carbón, acero y petróleo de Rusia meridional. 
Fue, sin embargo, no mayor independencia, sino dependencia a lo extranjero lo que resultó de la gran industria moderna cultivada en invernadero.

La existencia de crédito por supuesto que proporciona un poderoso aliciente para el desarrollo del capitalismo industrial. Cuando un noble feudal pide prestado dinero del usurero y paga los intereses de su deuda, su ingreso en consecuencia se reduce y finalmente se arruina, pero el capitalista industrial obtiene mayores ganancias si pide prestado dinero y paga sus intereses porque utiliza su dinero productivamente, no como el consumo improductivo del noble, para que, además del interés sobre el capital, obtenga ganancias. Si pide dinero al $4 \%$ y lo invierte para que obtenga un 10\%, entonces está ganando un 6\%. En esta forma, como capital financiero, el capital extranjero puede fácilmente acelerar el surgimiento de una clase capitalista en países económicamente atrasados.

Pero, para adquirir capital financiero, se necesita crédito, se debe ya tener un negocio que funcione bien, y en ese sentido, Rusia no tenía nada que ofrecer. El capital extranjero sin dudas fluyó en miles de millones hacia Rusia para desarrollar su industria pero sólo un mínimo porcentaje de este fue prestado a los empresarios rusos como capital para fundar y ampliar plantas industriales a gran escala. Al contrario, estas plantas en su mayoría fueron creadas directamente por capitalistas extranjeros y las mantuvieron en sus manos de manera tal que no sólo el interés sobre el capital sino todos los beneficios fueron acumulados por ellos y sólo los salarios permanecieron en Rusia. Este método para atraer capital extranjero produjo sólo el desarrollo de un fuerte proletariado, pero no de una clase capitalista fuerte, dentro de Rusia. Animó, más que obstaculizó, el empobrecimiento de Rusia.

Esta tendencia, sin embargo, se evidenció de la manera más clara y determinante en la agricultura, aquella rama de la producción que participa más tardía y débilmente de los efectos de la creciente productividad del trabajo en el modo de producción capitalista y que, más que cualquier otra, necesita de una población instruida para aprovechar las ventajas de los modernos recursos y métodos de producción. El capitalismo en Rusia no trajo a los campesinos escuelas mejoradas, el dinero para obtener fertilizantes artificiales o para mejorar las herramientas y maquinarias, sino que sólo aumentó la explotación. Mientras que en Europa Occidental el incremento de la explotación del campesinado por el estado y el capital fue de la mano con un crecimiento en la productividad del trabajo agrícola, en Rusia, al contrario, la explotación creciente del campesino, que se vio estimulada por el incremento de la competencia entre Rusia y las naciones capitalistas desarrolladas, trajo una constante caída en la productividad agrícola. El número de malas cosechas creció y además en cada hambruna el ganado era sacrificado antes que la gente sucumbiera al hambre. De este modo cada hambruna produce una reducción en el stock de ganado que en su momento conduce a una escasez de fertilizantes, un cultivo menos eficiente, y así a un mayor deterioro en la agricultura y a nuevas y peores malas cosechas. Pero toda la nación cae en la miseria junto con el campesino, ya que con él el mercado interno para la industria rusa se hunde y es el único mercado que ésta abastece porque no es competitiva en el 
mercado mundial; pero con la desaparición del campesino el estado también se enfrenta a su propia bancarrota a pesar de esa enorme riqueza natural con la que los corredores de bolsa de Europa Occidental se entusiasman cuando están dispuestos a poner más miles de millones a los pies del sangriento zar. ¡Si sólo esos millones hubieran sido usados para extraer esa riqueza y no para oprimir y masacrar a aquellos que a través de su trabajo son los únicos capaces de transformar esa riqueza natural en objetos de valor que pueden ser intercambiados en el mercado mundial por dinero!

La decadencia de la agricultura es, luego del ascenso del proletariado industrial, la causa principal de la presente Revolución rusa. Ha Llevado al estado al borde de la bancarrota financiera y creó condiciones que son insatisfactorias incluso intolerables, a todas las clases, condiciones que ellos no pueden soportar y de las que deben intentar escapar, una vez que han comenzado a moverse.

\section{La solución a la cuestión agraria.}

La manera más obvia de ayudar al campesino es incrementar su parcela de tierra. Casi todos los partidos concuerdan en eso. Pero, ¿es esto suficiente? ¿Cuán útil puede ser dar más tierras al campesino cuando ni siquiera tiene ganado suficiente o herramientas para trabajar adecuadamente su parcela actual? Tal vez le dará un alivio temporario pero la vieja miseria pronto prevalecerá nuevamente. Si el campesino va a ser ayudado en el largo plazo entonces deben tomarse previsiones que le permitan optar por más intensivos y más racionales métodos de cultivo. Debe tener ganado, herramientas y fertilizantes a su disposición, debe establecerse un sistema de educación elemental de primer nivel: en resumen, al campesino debe dársele, lo más rápido y completamente posible, aquello que por décadas se le ha retenido o quitado como consecuencia del progresivo endeudamiento del estado, su continuo incremento impositivo y su creciente incapacidad e indiferencia para realizar cualquier tipo de tarea cultural.

Sólo un régimen que sea capaz de hacer esto puede poner nuevamente a la agricultura campesina rusa, y con ella a todo el estado, sobre bases sólidas y de este modo poner fin a la revolución.

¿Es el absolutismo capaz de hacer esto? Si lo fuera entonces podría dominar la revolución. Si el zar tuviera la inteligencia y la fuerza de transformarse en un emperador campesino como Napoleón I él podría asegurar su régimen absolutista una vez más. Por lo general el campesino no tiene mucho interés en la libertad política de la nación. Normalmente su interés gira en torno a los asuntos de la aldea. Si viera que el zar cuida de sus necesidades económicas, se pondrá nuevamente de su lado.

Pero por fortuna esto es imposible. Incluso el primer Napoleón sólo estaba en la posición de traicionar la libertad política de Francia con la ayuda de los campesinos y el ejército reclutado de entre sus miembros porque él era el heredero de la revolución y 
porque la revolución ya había satisfecho las demandas de los campesinos y él simplemente aparecía como el protector de los logros que habían obtenido en y mediante la revolución.

Incluso el monarca más enérgico y previsor no puede vencer una revolución política por sí mismo realizando su objetivo económico. Para hacer esto tendría que ser no sólo más previsor sino también más poderoso que toda la clase dominante en cuyo seno vive y a cuyas expensas la meta económica de la revolución sólo puede ser lograda. Incluso si fuera posible para un solo individuo pensar y sentir, clara e inconfundiblemente, de una manera completamente opuesta a la del entorno en el que se ha movido desde su infancia, no hay un solo individuo, aún el más dotado, que sea capaz de desafiar a todo su entorno solo. El zar de Rusia tiene menos poder que nadie para hacer esto. Apenas muestre la más leve inclinación a llegar a un acuerdo con la revolución los fieles siervos del absolutismo acabarían con él.

Pero de Nicolás II no podemos siquiera esperar cualquier intento para romper significativamente con su entorno por cualquier asunto.

Por lo tanto este gobierno rechaza enérgicamente cualquier cosa que pudiera mejorar la miserable parcela de los campesinos incluso en una medida limitada. Les ofrece sólo promesas vacías, estafas y miserables fracasos. Pero ha pasado el tiempo en que el campesino se permitía ser engañado por todo esto. La revolución ya ha logrado tanto en el campo que el campesino quiere ver acción y juzga a cada partido por sus actos. Pero ¿qué es lo que espera de las acciones del gobierno, el cual asimila al zar? Los impuestos aumentaron pero no se les ofreció ninguna ayuda a las provincias donde las malas cosechas causaron hambrunas. Escuelas y hospitales cerraron por falta de recursos, los ferrocarriles se deterioraron porque su equipamiento no fue reemplazado, mientras que el zar necesita más dinero que nunca para soldados que usa para luchar contra su propia gente. Desde la invasión napoleónica el campesino ruso no ha visto un soldado enemigo en su país y se ha sentido seguro contra los enemigos extranjeros gracias al poder del zar. Ahora son los mismos soldados del zar quienes arrasan el campo como lo hicieron antes los Mongoles. De este modo todas las promesas que fueron hechas al campesino y que de vez en cuando lo llenaban de nuevas esperanzas de salvación final demostraron ser una miserable decepción y este descubrimiento hace su situación doblemente indignante y su ira disimulada dos veces más fuerte. La Duma, que le fue presentada como una salvación en este momento de necesidad, fue disuelta y el derecho a votar por una segunda Duma, que está actualmente siendo elegida, le fue arrebatado delante de sus narices. Frente a todo esto no es sorprendente que el pasado respeto ilimitado por el zar se haya transformado en un equivalente odio ilimitado por el zar.

Pero, ¿tienen los liberales la posibilidad de convencer al campesino a largo plazo?

Ellos ciertamente le están ofreciendo lo que quiere más que nada: más tierras. Al menos, muchos de ellos están demandando la expropiación de la gran propiedad territorial y su redistribución entre los campesinos. Pero ¿a qué precio? La propiedad debería ser 
tratada con consideración en la medida en que esto sea posible y eso significa que los terratenientes deberían ser completamente indemnizados. Pero ¿quién debe compensarlos? Quién más que el campesino, ya sea directamente si paga intereses sobre el precio de compra de la tierra cedida a él, o indirectamente si el estado indemniza al terrateniente. Pero entonces los intereses sobre el precio de compra recaen nuevamente en los proletarios y en los campesinos indirectamente en la forma de nuevos impuestos. ¿Qué podrían haber ganado los campesinos al aumentar su parcela de tierra? Nada en absoluto, porque los beneficios netos del incremento volverían en la forma de intereses o impuestos a los anteriores dueños de los latifundios. A menudo ni siquiera las apariencias externas cambiarían porque muchos campesinos ya trabajan partes de los latifundios en arrendamiento para incrementar su propia parcela. Si fueran dueños de lo arrendado y en lugar de intereses sobre la renta, ellos tuvieran que pagar un nuevo impuesto ¿cómo podrían estar mejor?

Es sólo a través de la confiscación de las grandes propiedades territoriales que los lotes de los campesinos pueden ser significativamente ampliados sin que se le impongan nuevas cargas. La expropiación de un solo estrato de la clase dominante sin compensación es por supuesto una medida severa. Pero no hay alternativa. La pauperización del campesinado fue tan lejos que no es posible pedirle que paguen compensaciones. Si los propietarios liberales hubieran tenido la energía y el desinterés para [imponerle al zar] formas políticas y una política de estado que les hubiera permitido una discusión amigable con el campesinado mientras era todavía solvente, ellos podrían haber preservado sus intereses en la propiedad de una manera u otra. Ahora es demasiado tarde. Además ellos tienen poco de que quejarse. Sus antepasados entendieron perfectamente cómo engañar a los campesinos más provechosamente cuando la servidumbre fue abolida: desde entonces se han aprovechado de su posición desesperada para el peor tipo de especulación y nunca han mostrado por el campesinado la menor consideración o respeto.

La confiscación de los latifundios es inevitable si se quiere ayudar a los campesinos. Pero los liberales están luchando firmemente contra esto. Sólo los partidos socialistas no retroceden con miedo.

Pero un incremento en la parte de las tierras de los campesinos está lejos de resolver la cuestión agraria de Rusia. Hemos visto que el campesino no sólo esta escaso de tierra, también le faltan técnicas y dinero. La decadencia de la agricultura rusa no será detenida en lo más mínimo porque la tierra y el suelo sean divididas de alguna manera diferente. Al contrario. Si las grandes propiedades, donde la agricultura es frecuentemente realizada sobre bases mucho más racionales, son divididas y reemplazadas por campesinos ignorantes sin recursos, la decadencia de la agricultura rusa sólo se acelerará si no se toman medidas enérgicas al mismo tiempo para incrementar la instrucción de los campesinos y su capital. 
Eso es, no obstante, imposible sin una profunda conmoción en la totalidad del sistema político actual que ha estado causando la presente miseria a ritmo creciente por 200 años. Mientras más profundamente esta miseria, que el absolutismo continúa aumentando visiblemente incluso ahora, esté arraigada, más enérgicos ataques serán requeridos contra las instituciones existentes y las relaciones de propiedad si queremos poner esta miseria bajo cualquier tipo de control.

Sin la abolición del ejercito permanente y la supresión de la carrera armamentística naval, sin la confiscación de toda la propiedad de la familia imperial y de los monasterios, sin la bancarrota del estado y sin la confiscación de los grandes monopolios aún en manos privadas (ferrocarriles, pozos petroleros, minas, siderurgia), no será posible recaudar la enorme suma que la agricultura rusa necesita si va a ser arrebatada de su terrible decadencia.

Pero está claro que los liberales retroceden ante tales gigantescas tareas, tales decisivas revoluciones en las relaciones de propiedad vigentes. Básicamente, todo lo que quieren es continuar con la política actual sin tocar los fundamentos de la explotación de Rusia por el capital extranjero. Ellos adhieren firmemente al ejército permanente, que por sí solo, según su mirada, puede asegurar el orden y salvar sus propiedades, y quieren obtener nuevos recursos para Rusia a través de nuevos préstamos, lo que es imposible si el interés de los anteriores no es pagado a tiempo.

El interés sobre la deuda pública y el militarismo ruso está costando ahora dos mil millones de marcos. Los liberales quieren seguir exprimiendo esta colosal suma del pueblo ruso año tras año y todavía imaginan que podrán al mismo tiempo llevar a cabo todas las grandes tareas culturales que el zarismo ha descuidado y ha tenido que descuidar para pagar por el militarismo y la deuda pública. Creen que la constitución de una Duma es suficiente para hacer aparecer miles de millones de la tierra.

Ellos con frecuencia evocan la gran Revolución Francesa. No siempre correctamente. Las relaciones en la Rusia actual son en muchas formas distintas de aquellas de Francia en 1789. Pero la diferencia no reside en el hecho que las condiciones rusas requieren medidas menos radicales que las francesas. Al contrario. Francia no estaba endeudada con países extranjeros, no sufría del mismo tipo de escasez de capital, su educación, agricultura e industria no estaban tan atrasadas como éstas en Rusia al compararlas con las del resto de Europa. Y aun así, la Asamblea Nacional no pudo salvar a Francia de la bancarrota del estado y de las confiscaciones. Y, si Francia pudo mantener su militarismo, sólo pudo hacerlo gracias a las victoriosas guerras revolucionarias que la pusieron en una situación desde donde pudo saquear media Europa y de este modo pagar los costos de la guerra. La Revolución Rusa no tiene perspectivas de cumplir con sus necesidades financieras de este modo. Debe acabar con el ejército permanente si pretende satisfacer al campesinado ruso.

El liberalismo es tan incapaz de hacer esto como el zarismo. Se puede recuperar nuevamente de manera temporaria pero pronto se desvanecerá. Esto sucederá tanto más 
rápido ya que está privado de elementos democráticos enérgicos porque la única clase con alguna importancia en la que puede confiar es la de los grandes terratenientes, una clase cuyo liberalismo naturalmente se diluye en cuanto la cuestión agraria sale a la palestra.

\section{Liberalismo y Social Democracia.}

El liberalismo de Rusia es de un tipo diferente al de Europa Occidental y sólo por esa razón es bastante erróneo presentar la gran Revolución Francesa simplemente como el modelo de la [revolución] rusa actual.

La clase dirigente en los movimientos revolucionarios de Europa Occidental fue la pequeña burguesía y, sobre todo, la de las grandes ciudades. Debido a su posición dual frecuentemente mencionada como la representante de la propiedad y el trabajo se convirtió en el nexo entre el proletariado y la clase capitalista, unió a ambos para luchar conjuntamente en la democracia burguesa que obtuvo su fuerza victoriosa de esto. El pequeño burgués se ve a sí mismo como un futuro capitalista y en ese sentido defendió los intereses del capital emergente. Pero él mismo creó el modelo para el proletario, quien por lo general provenía de los círculos pequeño burgueses, y al no tener aún una conciencia de clase independiente pedía sólo por la libertad y la oportunidad de ascender a la pequeña burguesía.

Además, la pequeña burguesía en las ciudades era la más numerosa, más instruida y económicamente más importante de las clases que constituían la masa popular. Pero las ciudades en sí se convirtieron en las sedes de los poderes gobernantes desde la Edad Media. Las ciudades regían el campo abierto y lo explotaban y la pequeña burguesía desempeñó un gran papel en este dominio y explotación: tuvieron éxito oprimiendo a los artesanos rurales y al mismo tiempo afianzaron su posición como una fuerza poderosa contra la nobleza y la aristocracia de las ciudades.

Nada como esto pasó en Rusia. Las ciudades allí, débiles, pocas en número y la mayoría de reciente desarrollo, nunca han logrado la poderosa posición que alcanzaron en Europa Occidental y la masa del pueblo nunca ha conocido cómo distinguirse de, y elevarse por encima de, la población rural, como lo ha hecho allá.

La masa de los artesanos urbanos se constituía de campesinos y numerosas formas de artesanía continuaron [realizándose] más en el campo que en la ciudad. Servidumbre y opresión, desamparo político y apatía eran iguales allí que aquí.

Fue sólo después de la abolición de la servidumbre que las semillas del interés político comenzaron a germinar entre las masas urbanas, pero esto ocurrió en las últimas décadas del siglo diecinueve al tiempo en que Europa Occidental el rol revolucionario dirigente de la pequeña burguesía se había finalmente agotado. Por una parte el proletariado se había hecho independiente y había sido poderosamente fortalecido mientras que por otra parte una enorme brecha se había abierto entre la pequeña burguesía y el capital. El 
pequeño burgués ya no ve más a los capitalistas como la clase a la que aspiraba ser elevado, sino como la clase que lo está oprimiendo y arruinando. Pero él ve a los asalariados como el elemento cuyas demandas están acelerando este proceso. Ya no es más el líder de la democracia que se une al capitalista y al trabajador en una lucha política común sino un descontento inescrupuloso que, decepcionado con la democracia, se enfurece simultáneamente contra ambos, proletario y capitalista y es influenciado por cualquier estafador reaccionario que le prometa algo atractivo.

De esta forma la pequeña burguesía de Europa Occidental se está haciendo cada vez más reaccionaria y poco confiable a pesar de sus tradiciones revolucionarias. La pequeña burguesía rusa entra al movimiento político sin tradición similar y bajo la completa influencia de la situación económica que también la está haciendo caer en Europa Occidental. Está, por lo tanto, mucho más inclinada que sus camaradas de clase europeos Occidentales al antisemitismo y la reacción, a la vacilación sin carácter que puede ser comprada a precio vil por cualquiera, al rol que el Lumpenproletariado ${ }^{36}$ jugó en la revolución de Europa Occidental: ese Lumpenproletariado con el que la burguesía está cada vez más ligado espiritualmente y con el cual, aún en Rusia, voluntariamente colabora. A través del progreso de la revolución puede eventualmente involucrarse de manera creciente en un movimiento de oposición pero no constituirá un apoyo seguro para los partidos revolucionarios.

Así, Rusia carece del firme apoyo de una democracia burguesa y le falta la clase que, a través de su interés económico común, puede fusionar burguesía y proletariado en un partido democrático unidos en la lucha común por la libertad política.

Incluso antes que la lucha revolucionaria comenzara, la clase capitalista y el proletariado en Rusia se colocaron en oposición directa uno frente al otro. Ambos habían aprendido de Occidente. El proletariado llegó derecho a la arena política no como parte de un partido democrático puro, sino como Social Democracia, y la clase capitalista se ha permitido a si misma ser intimidada por la mínima agitación por parte del proletariado: su principal preocupación es lograr un gobierno fuerte.

\footnotetext{
${ }^{36}$ N. de los Ed.: El Lumpenproletariado era, según Marx, esa parte de la clase de los no propietarios de los medios de producción que, por deficiencias de organización, articulación y conciencia eran presa fácil del soborno y la demagogia de los dictadores como Luis Bonaparte. En un inusual estilo gráfico, Marx describió este peligroso, aunque pintoresco, grupo de este modo:

Al lado de los decadentes rouès [libertinos/sans scrupule] con dudosos medios de subsistencia y dudoso origen, junto con los arruinados y aventureros vástagos de la burguesía, había vagabundos, soldados licenciados, ex-presidiarios, esclavos fugados de galeras, pícaros, charlatanes, lazzaroni, carteristas, estafadores, jugadores, maquereaus [proxenetas], guardias de burdeles, porteadores, literati, organilleros, ropavejeros, afiladores, hojalateros, mendigos, en pocas palabras, un conjunto indefinido, una masa desintegrada, tirada aquí y allá, que los franceses llaman la bohème. (MECW 11, p. 148-9)
} 
El núcleo del partido liberal en Rusia estaba formado por los grandes propietarios territoriales, a excepción de los latifundistas, es decir, precisamente la clase contra la que el liberalismo en Europa Occidental dirigió sus principales esfuerzos. Pero en Rusia, en contraste con Europa Occidental, el absolutismo recientemente ha sacrificado la agricultura al capital. El mismo proceso que fue completado en Europa occidental a finales de la Edad Media y en los inicios del absolutismo, la explotación del campo por la ciudad, fue practicada cada vez más por el régimen absolutista ruso en el siglo diecinueve, y manifiestamente condujo a la aristocracia terrateniente a la oposición. Esta posición opositora [de la aristocracia terrateniente] fue facilitada por el hecho de que esta esta entró menos en conflicto directo con el proletariado que el capital industrial de las ciudades, la otra clase opositora. Mientras el campesinado se mantuvo calmo, el terrateniente ruso pudo darse el lujo del liberalismo, como los Tories ingleses y algunos Junkers prusianos se permitieron rodearse de una atmósfera de simpatía hacia su fuerza laboral a los inicios de la industrialización.

Y se mantuvo calmo por un tiempo. La agricultura podía visiblemente decaer, el campesino hundirse en la miseria, diezmarse sus filas hambruna tras hambruna y arruinarse sus negocios, y él permanecería fiel a Dios y al zar. Ciertamente, se reveló de vez en cuando pero la causa de esos disturbios se atribuyó a penurias particulares antes que al completo sistema de dominación, que no fue reconocido como la fuente de dichas penurias.

Pero la transformación de las relaciones económicas fue gradualmente preparando un cambio en el panorama del campesino y en sus sentimientos en la segunda mitad del siglo diecinueve. La aldea estaba unida al comercio mundial que llevó sus productos al mercado mundial. El aislamiento de la aldea cada vez más llegaba a su fin. La conscripción general llevó a sus hijos a la gran ciudad donde fueron expuestos a nuevas impresiones y aprendieron a conocer nuevas necesidades. Al final, numerosos campesinos o sus hijos que habían perdido sus tierras se dirigieron a las fábricas y las minas y de este modo se unieron a la lucha de la clase proletaria y transmitieron sus impresiones de ésta [lucha] a sus camaradas dejados atrás en las aldeas de regreso a casa.

Así es como los cimientos en los cuales el absolutismo ruso descansaba fueron gradualmente socavados, pero se necesitaba un poderoso golpe para que esos cimientos colapsaran completamente. Eso pasó como resultado de la guerra en Manchuria y la subsiguiente rebelión del proletariado urbano. Los eventos que treinta años antes hubieran pasado sin dejar rastro en el campesino ruso, están provocando ahora una respuesta enérgica de éste. Se ha despertado y se dio cuenta que finalmente llegó la hora de poner fin a su miseria. Ya no lo oprime: lo provoca. De repente, se ve a sí mismo desde una nueva perspectiva: el observa al gobierno, a cuyo control se ha sometido, hasta ahora con confianza, como el enemigo que debe ser derribado. Él no va a permitir que otros piensen por el de nuevo, debe pensar por sí mismo, debe usar toda su inteligencia, toda su energía, toda su crueldad y abandonar todos sus prejuicios si va a sostenerse en el remolino por el 
que ha sido succionado. Lo que provocó que el campesino anglosajón y el pequeño burgués de los siglos diecisiete al diecinueve, emigrara traerá para el campesino ruso al inicio del siglo veinte, más rápida y violentamente, la revolución y la transformación del despreocupado, somnoliento e irreflexivo animal de costumbres en un enérgico, incansable e infatigable luchador [por un futuro] nuevo y mejor.

Esta increíble transformación está desarrollando una base firme para la nueva agricultura rusa que surgirá de las ruinas de la anterior pero también proporciona la garantía más segura para el triunfo final de la revolución.

Mientras tanto, cuanto más revolucionario se hace el campesino, más reaccionario es el terrateniente. Cuanto más el liberalismo pierde el apoyo que en él tenía, tanto más indecisos se vuelven los partidos liberales y tanto más giran los profesores liberales y abogados de las ciudades hacia la derecha para no perder completo contacto con su previa base de apoyo.

Este proceso puede conducir a un reforzamiento temporario de la reacción pero no puede suprimir la revolución en el largo plazo. Sólo acelera la bancarrota del liberalismo. Esto debe guiar a los campesinos cada vez más a los brazos de esos partidos que protegen sus intereses enérgica y crudamente y no se permiten ser intimidados por dudas liberales: los partidos socialistas. Mientras más dure la revolución, aún más este proceso debe continuar incrementando la influencia de los partidos socialistas también en el campo. Puede finalmente llevar a una situación en donde la Social Democracia llegue a ser la representante de las masas del pueblo y por lo tanto el partido vencedor.

\section{El proletariado y sus aliados en la revolución.}

Es tal vez adecuado aquí, como conclusión a este estudio expresar mi opinión sobre una consulta que mi amigo Plejánov ha realizado entre un grupo de camaradas no rusos sobre el carácter de la revolución rusa y las tácticas que los socialistas rusos deberían seguir. Es decir, me gustaría hacer sólo unas pocas observaciones sobre esas preguntas y no responderlas concretamente. Mientras creo que casi tres décadas de contacto cercano con los líderes destacados del movimiento revolucionario ruso me ubica en la posición de proporcionar a mis camaradas alemanes alguna información sobre este movimiento, también me siento como un novato frente a mis camaradas rusos cuando se trata de los asuntos rusos. Pero es, por supuesto, urgentemente necesario para nosotros socialistas de Europa occidental, formarnos un punto de vista definido sobre la Revolución rusa porque no es un evento local, sino internacional, y de la manera en que la valoremos dependerá la manera en que enfrentemos las próximas tareas tácticas de nuestro propio partido. Pero además no tengo motivo para ocultar mi propia opinión cuando los camaradas rusos me preguntan por ella.

El cuestionario contiene las siguientes tres preguntas: 
1. ¿Cuál parece ser el carácter general de la Revolución rusa? ¿Estamos frente a una revolución burguesa o socialista?

2. En vista a los desesperados intentos del gobierno ruso para suprimir el movimiento revolucionario ¿cuál debería ser la actitud del Partido Social Demócrata hacia los partidos democrático burgueses, que están luchando a su manera por la libertad política?

3. ¿Qué táctica debería proseguir el Partido Social Demócrata en las elecciones a la Duma para usar la fuerza de los partidos de la oposición burguesa en la lucha contra nuestro antiguo régimen sin violar la Resolución de Amsterdam?

Ninguna parte de la primera de estas preguntas me parece fácil de contestar. La era de las revoluciones burguesas, es decir, de las revoluciones en las que la burguesía era la fuerza impulsora, ha concluido también en Rusia. Allí también el proletariado ya no es más un apéndice y una herramienta de la burguesía, como lo era en las revoluciones burguesas, sino una clase independiente, con objetivos revolucionarios independientes. Pero dondequiera que el proletariado emerja de esta forma, la burguesía deja de ser una clase revolucionaria. La burguesía rusa en la medida en que es liberal y tiene una política de clase independiente, desde luego odia al absolutismo pero odia la revolución aún más, y odia el absolutismo porque lo ve como la principal causa de la revolución; y en la medida en que demande libertad política, lo hace sobre todo porque cree que es la única manera de poner fin a la revolución.

La burguesía por lo tanto no constituye una de las fuerzas impulsoras del presente movimiento revolucionario en Rusia y en ese sentido no podemos llamarla burguesa.

Pero no podemos usar esto como un motivo para llamarla socialista sin más preámbulos. No hay manera en que esta [revolución] pueda llevar al proletariado solo a la dominación política, a la dictadura. El proletariado ruso es demasiado débil y atrasado para eso. En cualquier caso es muy posible que en el curso de la revolución la victoria recaiga en el Partido Social Demócrata y la Social Democracia hace muy bien en mantener esta perspectiva de victoria ante sus seguidores porque uno no puede luchar exitosamente si ha renunciado a la victoria de antemano. Pero no será posible para la Social Democracia lograr la victoria solo a través del proletariado sin la ayuda de otra clase y como partido victorioso no será capaz de poner en práctica más de su programa que lo que le permitan hacerlo los intereses de la clase que apoya al proletariado.

Pero ¿en qué clase debería confiar el proletariado en su lucha revolucionaria? Si uno sólo echa un vistazo superficial a la política podría llegar a la conclusión que todas las clases y partidos que están esforzándose por la libertad política solo tendrán que trabajar juntos para obtenerla y sus diferencias deberían sólo ser resueltas luego que la libertad política haya sido ganada. 
Pero cada lucha política es una lucha de clases y de este modo también una lucha económica. Los intereses políticos son resultado de intereses económicos; es para proteger a éstos, y no para llevar a cabo ideas políticas abstractas, que las masas están sublevadas. Cualquiera que desee alentar a las masas hacia la lucha política debe mostrarles cuán estrechamente está unida a sus intereses económicos. No debe permitirse que esto quede en segundo plano si no se quiere llegar a un punto muerto en la lucha por la libertad política. La alianza entre el proletariado y otras clases en la lucha revolucionaria debe descansar sobre todo en un interés económico común, si va a ser duradera y victoriosa. Las tácticas de la social democracia de Rusia también deben estar basadas en ese tipo de interés común.

Existe un sustancial interés común durante todo el período de la lucha revolucionaria, sin embargo, sólo entre el proletariado y el campesinado. Este debe proporcionar las bases de toda la táctica revolucionaria de la social democracia rusa. La colaboración con el liberalismo sólo debe ser considerada cuando y donde la cooperación con el campesinado no sea por esto perturbada.

Es en el interés común entre el proletariado industrial y el campesinado en que la fuerza revolucionaria de la social democracia rusa se funda, es la posibilidad de su victoria y al mismo tiempo, los límites a la posibilidad de su explotación.

Sin los campesinos no podemos ganar en el futuro próximo en Rusia. No debemos, sin embargo, anticipar que los campesinos se harán socialistas. El socialismo sólo puede ser construido sobre la base de la gran empresa, es demasiado incompatible con las condiciones de la pequeña empresa para que sea capaz de surgir y afirmarse en medio de una población predominantemente campesina. Quizás pueda ser posible, si [el socialismo] llegara al poder en la industria a gran escala y en la gran empresa agrícola y, a través de su ejemplo, fuera capaz de convencer a los pobres campesinos e incitarlos a la imitación, pero el socialismo no puede prescindir de ellos. Y en Rusia, más que en otros lugares, las condiciones intelectuales y materiales para esto están ausentes. El comunismo de las aldeas rusas yace en ruinas y de ninguna manera significa comunidad de producción. También es imposible convertir la producción de mercancías moderna sobre la base de la comunidad aldeana en un modo superior de producción. Para esto es necesario al menos el marco del estado nacional, pero los agricultores rusos no son capaces de ninguna forma de producir sobre bases nacionales.

La presente revolución sólo puede conducir a la creación en el campo de un campesinado fuerte sobre la base de la propiedad privada de la tierra y a la apertura de la misma brecha entre el proletariado y la parte propietaria de la población rural que ya existe en Europa Occidental. Parece por lo tanto impensado que la presente revolución en Rusia esté llevando a la introducción de un modo socialista de producción, incluso si llevara a la social democracia al poder temporalmente.

Claramente, sin embargo, podemos experimentar algunas sorpresas. No sabemos cuánto tiempo más va a durar la Revolución rusa y las formas que hasta ahora ha adoptado 
sugieren que no tiene intenciones de llegar a un pronto final. Tampoco sabemos qué influencia va a ejercer sobre Europa Occidental y cómo enriquecerá al movimiento proletario allí. Finalmente, no tenemos todavía ninguna idea de cómo los éxitos logrados por el proletariado de Europa Occidental afectarán a los rusos. Haríamos bien en recordar que nos estamos acercando a situaciones completamente nuevas y problemas para los que ningún modelo anterior es adecuado.

Deberíamos probablemente ser justos con la Revolución rusa y las tareas que nos plantea si no la viéramos como una revolución burguesa en el sentido tradicional ni como una socialista sino como un proceso bastante único que está teniendo lugar en las fronteras entre la sociedad burguesa y la socialista, que requiere de la disolución de una [de ellas] mientras prepara la creación de la otra y que en cualquier caso trae a aquellos que viven en la civilización capitalista un paso significativo hacia su desarrollo.

\section{Bibliografía}

Baron, Samuel H. 1963, Plejánov, El padre del marxismo ruso, Madrid: Siglo XXI de España Editores, S.A.

Baron, Samuel H. 1995, Plekhanov in Russian history and Soviet historiography, Pittsburgh: University of Pittsburgh Press.

Day, Richard and Gaido, Daniel (eds. \& trans.) 2009, Witnesses to Permanent Revolution: The documentary record, Leiden: Brill.

De Leon, Daniel (Ed.) 1904, "Dresden-Amsterdam Resolution (Amsterdam Congress)" en Flashlights of the Amsterdam International Socialist Congress, Mountain View: New York Labor News, pp. 96-97.

Kautsky, Karl 1904b, "Vorrede zur polnischen Ausgabe der Kommunistischen Manifestes u.d.T.: Wie weit ist das Kommunistische Manifest veraltet?", Leipziger Volkszeitung, Nr. 169, 170, 172; July 23, 25, 27; Freie Presse, Elberfeld-Barmen, Nr. 175, 176, 177; July 28, 29, 30. 
Kautsky, Karl 1905, "Die Folgen des japanischen Sieges und die Sozialdemokratie“, Die Neue Zeit, 23. 1904-1905, 2. Bd. (1905), H. 41, 422, 43, S. 460-468, 492-499, 460-468. Versión inglesa en Day and Gaido 2009, pp. 373-408.

Kautsky, Karl (ed.) 1906a, 1649-1789-1905, St Petersburg: Luch.

Kautsky, Karl 1906b, Karl Kautsky "Triebkräfte und Aussichten der russischen Revolution“, Die Neue Zeit, 25. 1906-1907 1. Bd., H. 9-10, S. 284-290, 324-333.

Keep, J. L. H. 1963, The Rise of Social Democracy in Russia, Oxford: Clarendon Press.

Lenin, Vladimir I. 1906a, "Preface to the Russian Translation of K. Kautsky's Pamphlet: The Driving Forces and Prospects of the Russian Revolution”, en Lenin, Collected Works, Vol. 11, Moscow: Progress Publishers, 1962, pp. 408-413.

Lenin, Vladimir I. 1906b, “The Proletariat and its Ally in the Russian Revolution”, December 10 (23), en Collected Works, Volume 11, Moscow: Progress Publishers, 1962, pp. 365-375.

Marx, Karl 1852, The Eighteenth Brumaire of Louis Bonaparte en Karl Marx Frederick Engels Collected Works Vol. 11, New York: International Publishers, 1979, pp. 99-197.

Sammons, Jeffrey (Ed.) 2006, Heinrich Heine. Ludwig Börne: A memorial Rochester: Camden House.

Steenson, Gary P. 1991, Karl Kautsky, 1854-1938: Marxism in the Classical Years, Pittsburgh: University of Pittsburgh Press.

Trotsky, Leon 1906, Results and Prospects en The Permanent Revolution and Results and Prospects, New York: Pathfinder Press, 1978, pp. 29-122.

Trotsky, Leon 1907, "Vorwort", en Zur Verteidigung der Partei, in Schriften zur revolutionären Organisation, editado por Hartmut Mehringer, Reinbek bei Hamburg: Rowohlt, 1970.

Trotsky, Leon 1938, “Karl Kautsky” en Writings of Leon Trotsky (1938-39), New York: Pathfinder Press, 1969, pp. 98-99.

Trotsky, Leon 1939, “Three Conceptions of the Russian Revolution” en Writings of Leon Trotsky (1939-40), New York: Pathfinder Press, 1969, pp. 55-73.

Trotsky, Leon 2006, 1905 (compilación), Buenos Aires: CEIP.

Waldenberg, Marek 1980, Il papa rosso: Karl Kautsky, Roma: Editori Riuniti, 2 vols.

Recibido: 8 abril 2015 Aceptado: 28 mayo 2015 